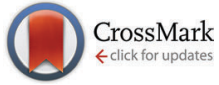

Cite this: J. Mater. Chem. B, 2015, 3, 6547

\section{Non-toxic, non-biocide-release antifouling coatings based on molecular structure design for marine applications}

\author{
Ayda G. Nurioglu, A. Catarina C. Esteves* and Gijsbertus de With*
}

\begin{abstract}
Marine biofouling generally refers to the undesirable accumulation of biological organisms on surfaces in contact with seawater. This natural phenomenon represents a major economic concern for marine industries, e.g. for ships and vessels, oil and wind-turbine sea-platforms, pipelines, water valves and filters, as it limits the performance of devices, materials and underwater structures and increases the costs related to transport delays, hull maintenance and repair, cleaning and desalination units, corrosion and structure break-down. In the last few decades, many efforts have been spent into developing efficient antifouling (AF) surfaces (coatings) combining advances in materials science and recent knowledge of marine chemistry and biology. However, the extensive use of toxic and harmful compounds in the formulations raised increasing health and environmental concerns leading to stricter regulations which pushed marine industries to search for new AF strategies. This review presents the recent research progress made in green strategies for AF coatings using non-toxic, non-biocide-release based principles for marine applications. The two main approaches, detachment of biofoulants or preventing biofoulants attachment, are reviewed in detail and new promising routes based on amphiphilic, (super)hydrophilic, and topographic (structured) surfaces are highlighted. The chemical and physical aspects of the AF mechanisms behind the AF strategies reviewed are emphasized, with special attention to the early stages of biofoulant adhesion, keeping the focus on the materials' molecular structure and properties which allow obtaining the final desired antifouling behaviour.
\end{abstract}

Received 3rd February 2015, Accepted 22nd June 2015

DOI: $10.1039 / c 5$ tb00232j

www.rsc.org/MaterialsB

Laboratory of Materials and Interface Chemistry, Department of Chemical Engineering and Chemistry, Eindhoven University of Technology, Eindhoven, Netherlands.E-mail: a.c.c.esteves@tue.nl, g.dewith@tue.nl

Catarina Esteves is an Associate Professor at the Chemical Engineering and Chemistry Department of Eindhoven University of Technology since 2009. She received her PhD in 2007 from the University of Aveiro, in Portugal. During the PhD period, she was a visiting researcher at Carnegie Mellon University (Prof. K Matyjaszewski, USA) and the University of Manchester (Prof. P Hodge, UK). She is an experienced researcher on the synthesis and characterization of (nano)materials: polymers, inorganic and composites in general. Since the last 5 years, her research has focused on functional polymers and surfaces, smart materials and coatings, surface modification and reversible/ responsive polymers and surfaces. Within the smart coatings topic she investigated self-healing, superhydrophobic/superhydrophilic materials, antifouling, reversible, switching and temperatureresponsive polymers and surfaces. Her research has been reported on more than 30 scientific peer-reviewed publications, 3 (co)-authored book chapters and several social magazines and media reports.
Gijsbertus de With is full professor in materials science. He graduated from Utrecht State University and received his $P h D$ in 1977 from the University of Twente on the 'Structure and charge distribution of molecular crystals'. In the same year he joined Philips Research Laboratories, Eindhoven. In 1985 he was appointed part-time professor and in 1996 he became full professor at the Eindhoven University of Technology. Since 2006 he has also been chairman of the Soft Matter CryoTEM Research Unit. His research interests cover structural and interfacial phenomena in relation to the processing and behavior of multi-phase materials. He has (co)-authored more than 250 research papers and holds about 20 patents. Throughout his career he has cooperated with other researchers, both from academia and industry. He is a member of the Advisory board of the J. Eur. Ceram. Soc., co-organised the first Eur. Ceram. Soc. Conference and has been co-organizer of the annual Coatings Science International conferences for 10 years. In 2006 his two-volume monograph Structure, Deformation, and Integrity of Materials was published, while in 2013 his book Liquid-state physical chemistry was released. 


\section{Marine biofouling}

Marine biofouling can be defined as the undesirable accumulation of microorganisms, algae and animals on artificial surfaces immersed in seawater. The fouling process starts from the moment the surface is immersed in water and takes place in three main stages: ${ }^{1}$ formation of a conditioning film, microfouling and macrofouling (Fig. 1). The conditioning film, comprised of organic molecules (e.g. proteins) attached to the surface, forms within the first minutes and sets the scene for further attachments. In the next hours bacteria settle in, in two phases: first, by an instantaneous ( $\sim 1$ minute) and reversible attachment via hydrodynamic and electrostatic interactions and second, via an irreversible attachment which occurs in the time scale of a few hours and involves covalent bonding between the bacteria and the substrate. ${ }^{1,2}$

The combination of the conditioning film and the slime of living and dead bacteria cells generates the first stage of microfouling, so-called the primary film. Further on, diatoms colonies, macroalgae and protozoa spores settlement increases the microfouling extent within the first 2-3 weeks, originating the secondary film. Finally, this microfouling stimulates the settlement of algae, spores and animal larvae, followed by the attachment of an adult marine organism, which is called macrofouling. Biofouling in marine environments is therefore, a relatively fast, dynamic and cumulative process which spans over several size and time scales and constitutes a complex problem with several forefronts.

Even though the aforementioned timeline is an acceptable conspectus, there is neither a well-defined, nor a universal agreement on the type of species attached and the precise timeline of the settlement. First, the species and their attachment time vary significantly depending on the location, as the environmental conditions such as salinity $(\mathrm{pH})$, temperature, nutrient levels and solar irradiation are different. Even if the location is fixed, the fouling behavior can change with season due to the differences in seawater temperature and day light irradiation. ${ }^{3}$ Second, for fixed locations biodiversity is another problem since more than 4000 different fouling species co-exist in the oceans. This significant variation of species, together with the variation of the local conditions and the different attachment mechanisms involved, makes it impossible to create a single (universal) strategy to avoid marine biofouling.

Independent of these variations, biofouling has been and currently is globally important due to the environmental and significant economic impact; the estimated cost for transport delays, hull repair, cleaning and general maintenance is 150 billion USD per year. ${ }^{3,4}$ The most undesirable effect of biofouling is the high frictional resistance for ship hulls due to the roughness generated by the attachment of marine organisms to the surface. Microfoulants cause an increase of $1-2 \%$ in the frictional resistance ( $\sim 100 \mu \mathrm{m}$ range), whereas macrofoulants may cause an increase between $10-40 \%{ }^{4}$ ( $\sim 1 \mathrm{~mm}$ range), as shown in Fig. 1 .

This considerable augmentation of frictional resistance, together with the weight increase by the fouled organisms, leads to significant speed reduction and loss of manoeuvrability of ships and vessels. Therefore, maintaining the required speed and navigation settings requires higher fuel consumption which increases the financial costs and the emission of harmful compounds into the environment. The United States (US) Naval Sea Systems Command estimates that biofouling on ship hulls results on average in a speed loss of approximately $2 \%$ and can increase fuel costs from 6 to $45 \%$, depending on the size of the ship. ${ }^{5}$ In order to avoid increasing the fuel consumption, the frequency of dry-docking operations for fouling removal and ships hull repairs has to be decreased. ${ }^{6}$ This entails personnel resources, machinery efforts, loss of time and the generation of waste potentially harmful for health and environment. Furthermore, the abrasion of the ship hull and its protective coatings generates other problems like discoloration, corrosion and the potential release of its products into the seawater. Finally, fouled ships also consist of a source of cross-biocontamination since they can carry marine species into environments where they are not naturally present. In summary, marine biofouling leads to high fuel consumption, generation of chemical waste, general increased costs and dispersal of invasive marine species. The search for solutions to these problems stimulated extensive research on coatings which prevent marine fouling, i.e., antifouling (AF) coatings. In this paper we discuss the most recent green strategies for AF coatings using non-toxic, non-biocide-release based approaches for marine applications.

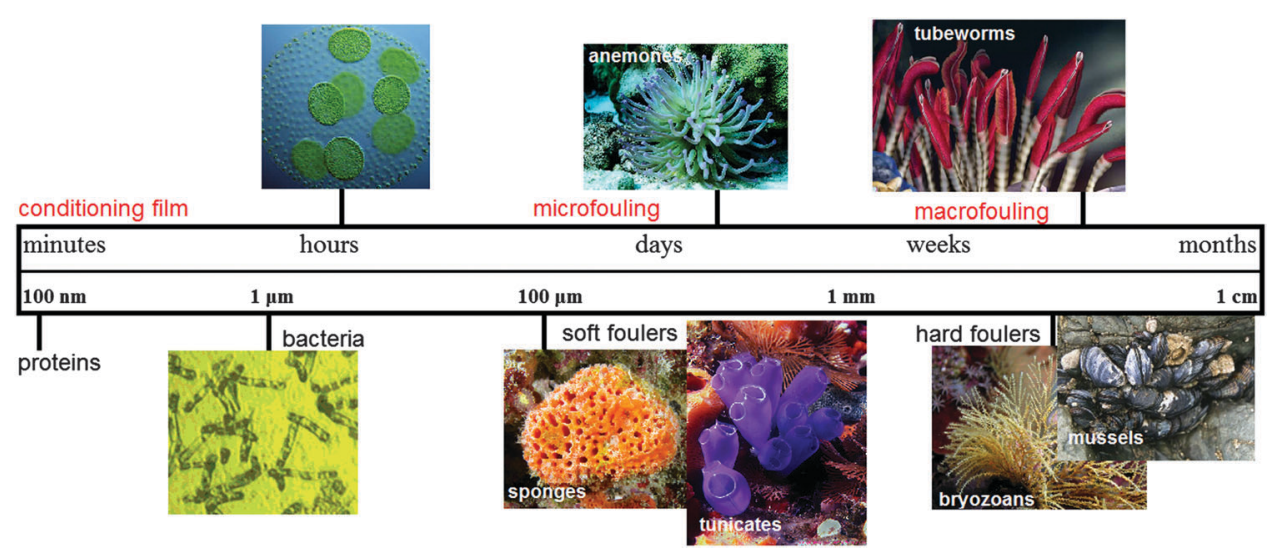

Fig. 1 Different phases of marine biofouling: Time-line evolution and respective roughness increase. 


\section{Evolution of marine coatings towards 'green' antifouling approaches}

Coating technology has been applied to ships and vessels since very ancient times, either to protect the wood from shipworms or to prevent fouling. The first materials to be used were natural products like waxes, tar or asphalt. Later on, copper and lead sheathings were introduced by the Phoenicians and Carthaginians. Although lead sheathing could not prevent fouling, it successfully protected the wooden ships from shipworms; hence, it remained the most widespread material for marine coatings nearly until the end of the 17th century. In the meantime different alternatives were tried, such as coatings containing arsenic and sulphur mixed with oils (5th century) or pitch blended with oils, resins and tallow (13-15th century). Lead sheathing was finally abandoned in the late 17th century, as it caused severe corrosion of the iron components of the ships. Contemporaneously, the underwater use of copper was introduced in the beginning of 17th century for wooden ships, and a first patent on antifoulants based on copper was already registered in 1625 , by William Beale. However, the reason for the antifouling effect of copper was not known until the beginning of the 19th century, when Sir Humphrey Davy finally discovered that it was in fact due to copper dissolution into seawater.

In the late 18th century, the development of iron ships really boosted the search for new AF coatings. Various materials were investigated, namely non-metallic sheathings such as felt, canvas, rubber, ebonite, cork, paper, glass, enamel, glaze and tiles. The insertion of a layer between iron and copper, to isolate the copper sheathing from the iron hull and eventually prevent corrosion, was also attempted. Cork, rubber, plain brown paper and felt soaked in tar were used for isolation purposes. One of the new approaches tried in the 19th century was wooden sheathing, which was compatible with copper sheathing but not costefficient. Since no candidate seemed to provide an ideal replacement to the former metal sheathings, with reduced corrosion effects, the interest in the antifouling (AF) coatings continued growing. In the middle 19th century, paints with dispersed biocides - toxic compounds for the marine biological organisms - became the main focus for marine AF applications. The systems were composed of at least three main elements: antifoulants (e.g. copper oxide, arsenic and mercury oxide), solvents (mostly turpentine oil, naphtha and benzene) and binders (e.g. linseed oil, shellac varnish and tar). Although the idea of applying slightly soluble coatings containing toxic materials over a varnish primer seemed to be reasonable, the abrasion and uncontrollable dissolution rate impeded these systems to be successful. Following up, two types of paints were concurrently developed to solve these problems: the 'Italian Moravian', a mixture of rosin (a natural resin extracted from plants) and a copper compound, and the 'hot-plastic paint' composed of copper sulphate with a metallic soap composition. These AF paints still needed, however, to be applied over shellac or varnish primer to prevent corrosion. These systems were widespread in the late 19th century, but they were too expensive and had short life span. Several improved versions were developed in the early 20 th century by varying the antifoulants, the solvents or inserting other biocide-additives. Further improvements were able to increase the lifetime of these coatings up to 18 months. Advances on the application process were also achieved and the replacement of the increasingly expensive shellac by rosin reduced significantly the costs.

The real revolution in AF systems started, however, in the 1940s when new synthetic petroleum-based resins were developed, yielding polymer-based coatings with improved mechanical properties. Concurrently, the growing safety and health concerns prompted the use of airless spraying techniques and banned the use of organo-mercury and organo-arsenic compounds. In the mid 1950s, tributyltin (TBT) moieties were first introduced as antifouling agents. The use of triorganotin derivatives increased in a short time due their wide-range activity, absence of corrosion effects and of colour. Also, since a change of the anion seems to have no significant effect on the biological activity of triorganotin compounds, variation of different parameters such as solubility and leaching, made variations of the formulations possible. Taken all together, these properties seemed to be the answer to a number of problems of the previous AF systems. In the late 80s, environmental concerns with TBT started to be raised; oysters showed a significant shell-thickening, some marine organisms became locally extinct (e.g. Nucella) due to an inability of reproduction ${ }^{7}$ and bioaccumulation of tin was detected for fish, seals and even ducks. ${ }^{5,6}$ TBT-based AF coatings on ships and vessels were then restricted in most European countries and finally banned worldwide in 2008 , as a follow up from an International Convention which was held in $2001 .^{8}$

With new and strict environmental and health restrictions imposed to materials for marine applications, it became imperative to find alternative materials and strategies for $\mathrm{AF}$ coatings. The current research on this subject may be divided in two main approaches: biocide-release and non-biocide-release based AF coatings (Fig. 2).

Biocide-release based AF coatings apply the same principle as the TBT-based systems, but with non-toxic components. These coatings are based on the dispersion of additives in different types of polymeric binders which release the pigments into the seawater over time. Depending on the release mechanism, it is possible to differentiate the release based AF coatings into two main categories, insoluble or soluble matrix coatings (Fig. 2a and c, respectively).

Insoluble matrix coatings - often also referred to as contact leaching - contain AF pigments embedded in a polymer matrix that does not dissolve, polish or erode after immersion in water (Fig. 2a). Typically they are mechanically robust, not susceptible to cracking and generally resistant to atmospheric exposure in non-aqueous environments (i.e., stable to oxidation and photodegradation) because a water-insoluble matrix is used. However, after a certain service time, the pigments dispersed in the matrix have to diffuse through such a thick leached layer that the rate of release becomes lower than the minimum value required to prevent fouling, which causes short lifetimes of around 12 to 18 months. Due to this short lifetime, insoluble matrix coatings are currently less commonly used. 

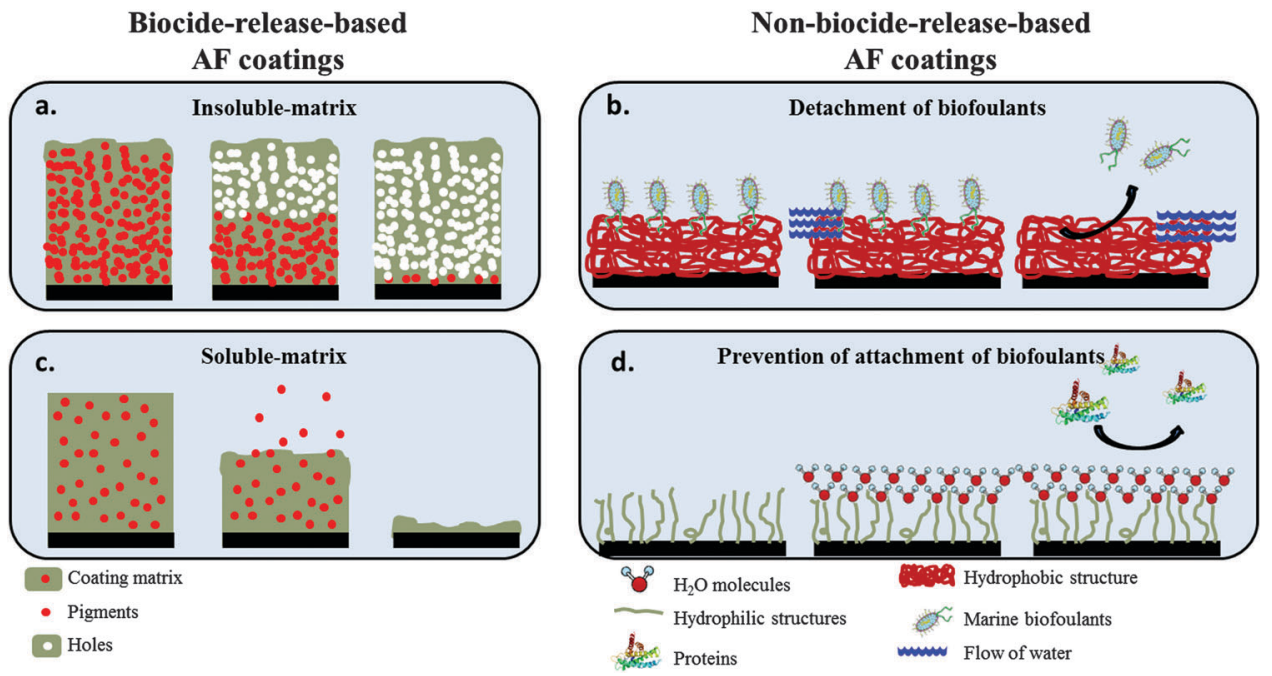

Fig. 2 Schematic of marine AF coating approaches: ( $a$ and c) Biocide-release based strategies; ( $b$ and d) non-biocide-release based strategies

The soluble matrix coatings (Fig. 2c) typically contain high proportions of rosin with a binder incorporated which can be dissolved in seawater. ${ }^{9,10}$ More recently, tin-free organically synthesized resins, commonly addressed as controlled depletion paints (CDPs), also started to be used. Other independent categories, such as self-polishing copolymers (SPC), ${ }^{9}$ have been proposed as well. In both cases, the balance between good AF characteristics (high resin content) and good mechanical properties (higher co-binder and plasticizer content) is important. As this balance is achieved, these paints are less expensive as compared to insoluble matrix coatings, have a good roughness control and have a lifetime longer than 3 years, and therefore nowadays they are preferred. For further details of the biociderelease based AF coatings approaches, we refer the reader to several other reviews available. ${ }^{11}$

The current review focuses on non-biocide-release based AF coatings approaches which are highly preferred since they are the greener alternatives, compliant with the current environmental and health regulations. Within the non-biocide-release approach there are two main strategies based on their working principle: 'detachment of settled biofoulants' by the water flow upon ship navigation (Fig. 2b) and 'prevention of attachment' of biofoulants (Fig. 2d). In the next section the important principles to be taken in consideration to design non-biociderelease AF approaches for polymer coatings will be discussed in detail.

\section{Principles for preventing biofoulant adhesion or promoting biofoulant detachment}

The non-biocide-release based AF coatings discussed here can be divided into two main strategies according to their action mechanism: 'detachment of biofoulants' and 'prevention of attachment' of biofoulants (Fig. $2 \mathrm{~b}$ and d, respectively). In order to apprehend the differences between these strategies, two important concepts should be described, settlement and adhesion strength. Settlement is defined as the irreversible attachment of biofoulants at the surface, followed by the secretion of an adhesive and consequent loss of motility. ${ }^{12}$ In relation to settlement, adhesion strength refers to the ease with which settled biofoulants are removed from a surface when exposed to a hydrodynamic shear stress. The strategy of 'prevention of attachment' aims to avoid settlement, while the 'detachment of biofoulants' seeks to reduce the adhesion strength as much as possible for an efficient removal of the settled organisms. To design such AF strategies it is essential to have fundamental knowledge on the phases of the fouling formation and on the theoretical and practical aspects which lead to adhesion of biological organisms on surfaces. The different phases of biofouling formation were investigated from different technological perspectives, namely biological ${ }^{13}$ and chemical-physical ${ }^{14,15}$ which are described in detail in several other reviews. ${ }^{8,11,16,17}$ According to Delauney et al. ${ }^{18}$ five main phases are involved in the biofouling process:

(1) Adsorption of organic and inorganic macromolecules (mostly proteins) immediately after immersion, forming the conditioning film;

(2) Transport of microbial cells to the surface and immobilization of bacteria;

(3) Bacterial attachment to the substrate consolidated through extracellular polymer production (secretion of a natural adhesive), forming a microbial film on the surface;

(4) Development of a more complex community of multicellular species, microalgae, debris, sediments, etc... on the surface;

(5) Attachment of larger marine invertebrates such as barnacles, mussels and macro-algae.

The biofouling phases and adhesion mechanisms may differ for different marine species and there is no universal consensus. The debate is still ongoing - some macro-organisms may not need the presence of the conditioning film to start the settlement process, or the five stages can actually occur in parallel. 
Nevertheless, some principles for antifouling based on these five main phases have been established. One of the most critical points is to avoid the formation of a conditioning film, i.e., to prevent the adhesion of proteins which will trigger the settlement process. The 'prevention of attachment' strategies focus on this principle (Fig. 2c). On the other hand, the focus of the 'detachment of biofoulants' strategies is on the release of the settled biofoulants before the secretion and differentiation of the natural adhesives takes place, i.e., to keep the adhesion strength at a minimum value (Fig. 2d).

The adhesion of marine organisms has been reported to be strongly related to the surface energy of materials. A correlation between relative adhesion of biofouling organisms and the critical surface tension of the substrate $\gamma_{c}$ - numerically equivalent to the surface tension of a liquid $\gamma_{\mathrm{L}}$ which perfectly wets the surface, i.e., a liquid with $\theta=0^{\circ}$ - was proposed by Baier. ${ }^{19}$

Generally, the Baier curve, ${ }^{19}$ displaying the degree of biological fouling retention $D$ as a function of the critical surface tension $\gamma_{c}$ (Fig. 3), exhibits a minimum in $D$ for $\gamma_{c}$ in the range of 20 to $30 \mathrm{~mJ} \mathrm{~m}^{-2}$. It also possibly shows a maximum at about $60 \mathrm{~mJ} \mathrm{~m}^{-2},{ }^{19-22} \dagger$ reproduced without comment by others. ${ }^{16}$ Other researchers ${ }^{24-27}$ have confirmed the minimum but do not show the maximum, nor comment on it. Still others find a response to surface energy opposite of that predicted by the Baier curve, i.e., attachment density increased with decreasing surface energy. ${ }^{28-30}$ With respect to the Baier curve, another remark must be made. Not all authors use the critical surface tension but some are using just the (regular) surface tension to assess the adhesion. Since critical surface tension and surface tension are not identical, this leads to some confusion.

Meyer $e t a l .^{31}$ have tested a set of silicone elastomer coatings designed for use as fouling-release paints in seawater environments. The low critical surface tension data did not discriminate sufficiently the tested coatings, and the authors attributed the organism-specific, improved fouling-release performance of the silicon-based coatings to the surface-active eluates, resulting from hydrolysis and fragmentation of the superficial silicone polymer, which inhibit cross-linking of the natural adhesives of fouling organisms. However, this cannot fully explain the presence of a minimum in the Bayer curve.

A possible explanation is given by Dexter ${ }^{24,32}$ on the basis of the Girifalco-Good theory. ${ }^{33}$ This explanation critically depends on the balance between the interaction factors for (sea)water-substrate and fouling agent-substrate rendering a minimum in $\gamma_{\mathrm{c}}$ of about $10 \mathrm{~mJ} \mathrm{~m}^{-2}$. An alternative explanation is provided by Schrader ${ }^{34}$ on the basis of Fowkes theory. ${ }^{35}$ Here the explanation is that, at the minimum, the dispersion forces of liquid and substrate are similar, while both excess dispersion interaction of liquid or substrate results in an increase of overall interaction. This minimum interaction is approximately equal to the dispersive component of the surface tension of liquid water, $\gamma_{\mathrm{L}}^{\mathrm{D}}$, which is about $22 \mathrm{mN} \mathrm{m}^{-1}$, as estimated

$\dagger$ The existence of the maximum is much less supported then that of the minimum, although high energy surfaces such as that of Pyrex glass can show a considerable reduced interaction, see e.g. ref. 23.

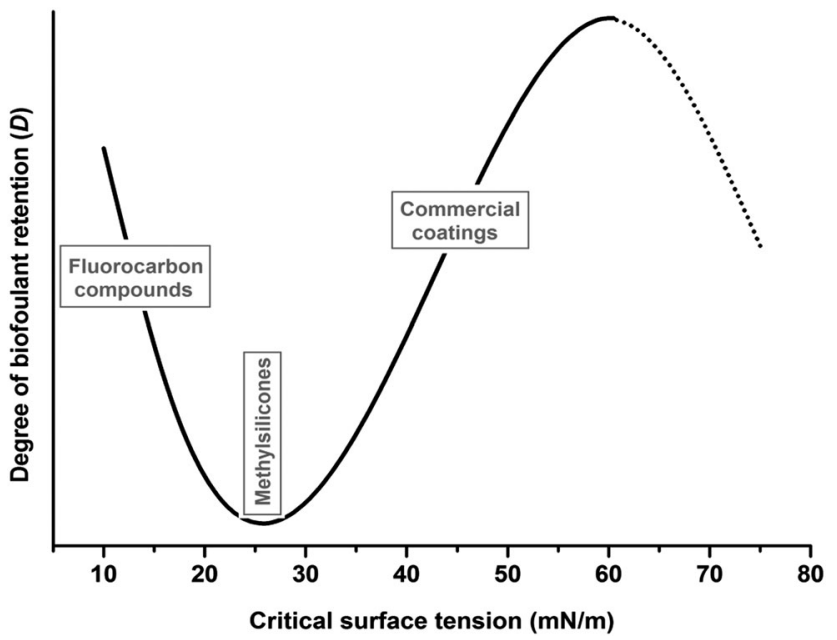

Fig. 3 The Baier curve demonstrating the relative amount of biofouling versus the critical surface tension of various chemical substrates. Adapted from ref. 19.

by Zisman. ${ }^{36}$ In aqueous systems, water must rewet the surface when proteins and cells are removed, and for surfaces with a surface energy of $22 \mathrm{mN} \mathrm{m}^{-1}$ the "thermodynamic cost" for water is minimized. This means that for surfaces having this minimum critical surface tension, the effort to detach the settled biofoulants is minimal since we are at the minimum of adhesion strength. While Dexter's ${ }^{24}$ explanation has been generally ignored, Schrader accepts that the critical surface tension represents the surface energy. This is, however, true in the presence of dispersive interactions only. Recently more or less straightforward applications of the van Oss-Good-Chaudry theory ${ }^{37}$ have been used as well ${ }^{38-40}$ but without referring to earlier explanations. However, these theories of components-ofsurface-tension have been seriously criticized by Neumann et al., ${ }^{41,42}$ summarized by 'for a given solid, the contact angle depends only on the liquid surface tension, not directly on the intermolecular forces which give rise to these surface tensions'. These authors showed that the components-of-surface-tension approach can lead to unexpected classifications (e.g., methanol being classified non-apolar $\ddagger$ and claim that the information on intermolecular interactions that can be obtained from this approach, determinant for adhesion, is rather meager. However, in defense to the surface-tension-components approach one should refer to Lyklema ${ }^{43}$ who provides arguments for the validity of this approach if exercised with sufficient care. Also DLVO theory ${ }^{44}$ has been used to explain biofouling phenomena, without comparing to other approaches. However, since bacteria cannot be entirely represented as hard spheres, one might expect a further influence of flexibility upon the adhesion behavior. For a brief revision of each of theories involved, which falls out of the scope of the current review, we refer to Hiemenz et al. ${ }^{45}$

Altogether, this boils down to that the Baier curve minimum is reasonably well established experimentally but that an unequivocal explanation for this minimum is absent while an

† See page 239 of ref. 41. 
explanation for the (possibly present) maximum has not been given. Hence, if we want to design AF coatings via the 'detachment of biofoulants' strategy (Fig. 2b), we should seek for surfaces within this range of critical surface energy values, typically hydrophobic materials such as fluorocarbons, hydrocarbons and poly(dimethylsiloxanes) (PDMS).

For surfaces with much higher critical surface tension, some other AF principle can be explored. These surfaces typically have a very strong hydrophilic character and retain a permanent hydration layer. The attachment of biofoulants to the surface is therefore thermodynamically unfavourable as it would require dehydration and confinement of a system which previously had high conformational entropy. Hence, to design coatings via the 'prevention of attachment' strategy (Fig. 2d) it is preferred to use materials which are in the maximum critical surface tension range of the Baier curve. Most of the current commercial coatings use materials which fall within this description, amongst which poly(ethylene glycol) (PEG) is the most common.

Several other important aspects related to the materials characteristics that can be used to optimize the AF strategies play a role in the biofouling process. The surface chemical and physical properties, the surface and bulk mechanical and structural properties (elastic modulus, coating thickness, etc.) and the topography (i.e. 'physical' constraints) are equally important parameters which will also determine de AF character and ultimately the life-span of the material as well. These aspects are discussed in detail in the following sections, according to their relevance to each of the individual non-biocide-release based AF strategies.

\section{Non-toxic, non-biocide-release antifouling coatings}

The main idea of non-toxic, non-biocide-release based approaches for AF coatings is to provide moieties with the desired functionality at the surface, considering the aforementioned principles of adhesion. The two main strategies within this approach are (i) 'detachment of biofoulants' mostly from 'hydrophobic surfaces' using the hydrodynamic shear flow caused by the movement of the ship (Fig. 2b) and (ii) 'preventing the attachment' of biofoulants by applying a 'hydrophilic coating' which retains a hydration layer (Fig. 2d). In the following sections we describe the most recent works reported for both strategies and the principles behind it.

\subsection{Detachment of biofoulants}

Coatings applying the 'detachment of biofoulants' strategy started to be explored within the same time-span as self-polishing copolymers (SPC); however, the efficiency and economic benefits of TBT-based containing coatings delayed the improvements in this field. After the prohibition of organotin derivatives, research on the 'detachment of biofoulants' coatings was accelerated. The main objective for these AF coatings is to create only weak connection points between the surface and the biofoulant, so that it will easily fail due to the stress caused by the weight of fouling or the hydrodynamic flow caused by the ship's navigation. As discussed before, a minimum of adhesion strength is targeted and detachment should occur before the settlement is consolidated by the organic adhesives segregated by the bioorganisms, e.g. bacteria and microbes, leading to the formation of a stable biological film.

Brady et $a l .{ }^{46}$ investigated the structural and mechanical requirements for polymers to be resistant towards strong chemical bonds with bio-organisms.

In what concerns the structural requirements, four principal adhesion mechanisms can be considered to avoid the adsorption or wetting of the surface by organic adhesives. A first mechanism deals with the chemical interactions. Although dispersive interactions cannot be avoided, dipolar, ionic and covalent bonds can be excluded by using nonpolar and nonreactive moieties in the surface. Preferably, these moieties should be conformationally mobile. A second possible mechanism is based on electrostatic interactions. These can be eliminated by avoiding the presence of heteroatoms, polar and ionic groups at the surface. A third adhesion mechanism occurs by mechanical interlocking. Even if chemical bonding and electrostatic interactions are hindered, biofoulants may still be able penetrate into surface cavities and adhere to the inner surfaces. Hence, rough and porous surfaces should be avoided. Finally, the fourth mechanism concerns adhesion on unstable surfaces which can rapidly rearrange in the presence of the biological adhesives, creating temporary microvoids and enabling inward diffusion of the biofoulants. In this case, rearrangements and mobility of chemical groups should be prevented by using closely-packed functional groups and cross-linking them in order to hinder diffusion. Ideally, these four requirements should be combined in a single material-surface. Although the fulfilment of these structural requirements will reduce the adhesion strength, it will still not completely avoid adhesion. ${ }^{46}$

The mechanical properties of the coatings should also be considered when targeting weak adhesion facilitating the detachment of biofoulants. In fact, Brady ${ }^{46}$ reported that in addition to the critical surface energy of the substrates, as previously reported by Baier ${ }^{19,24}$ and others, two additional properties are important in breaking adhesive joints: the elastic modulus and thickness of the coatings. Brady et al. ${ }^{46}$ worked with several polymers (as listed in Table 1) and came to the conclusion that there is a linear relationship between relative adhesion and the square root of the product of critical surface free energy and elastic modulus of the polymers (Fig. 4). These results can also be found in the revision by Townsin et al. $^{47}$

Although several studies have been conducted to interpret the materials properties necessary to design an efficient $\mathrm{AF}$ coating, the most acknowledged aspects were summarized by Brady. ${ }^{48}$ The polymers should have:

- A flexible, linear backbone which introduces no undesirable interactions;

- A sufficient number of surface-active groups which are free to move to the surface and impart a surface energy in the desired range;

- A low elastic modulus; 
Table 1 Physical properties of polymers investigated for AF surfaces. Adapted from ref. 46

\begin{tabular}{lllll}
\hline$\#$ & Polymer & $\begin{array}{l}\text { Relative } \\
\text { adhesion }\end{array}$ & $\begin{array}{l}\text { Critical surface free } \\
\text { energy }\left(\gamma_{\mathrm{c}}\right) \mathrm{mN} \mathrm{m}^{-1}\end{array}$ & $\begin{array}{l}\text { Elastic modulus } \\
(E) \mathrm{GPa}\end{array}$ \\
\hline 1 & Poly(dimethylsiloxane) & 6 & 23.0 & 0.002 \\
2 & Poly(hexafluoropropylene) & 21 & 16.2 & 0.5 \\
3 & Poly(tetrafluoroethylene) & 16 & 18.6 & 0.5 \\
4 & Poly(vinylidenefluoride) & 18 & 25.0 & 1.2 \\
5 & Poly(ethylene) & 30 & 33.7 & 2.1 \\
6 & Poly(methyl methacrylate) & 48 & 41.2 & 2.8 \\
7 & Poly(styrene) & 40 & 40.0 & 3.9 \\
8 & Nylon 66 & 52 & 45.9 &
\end{tabular}

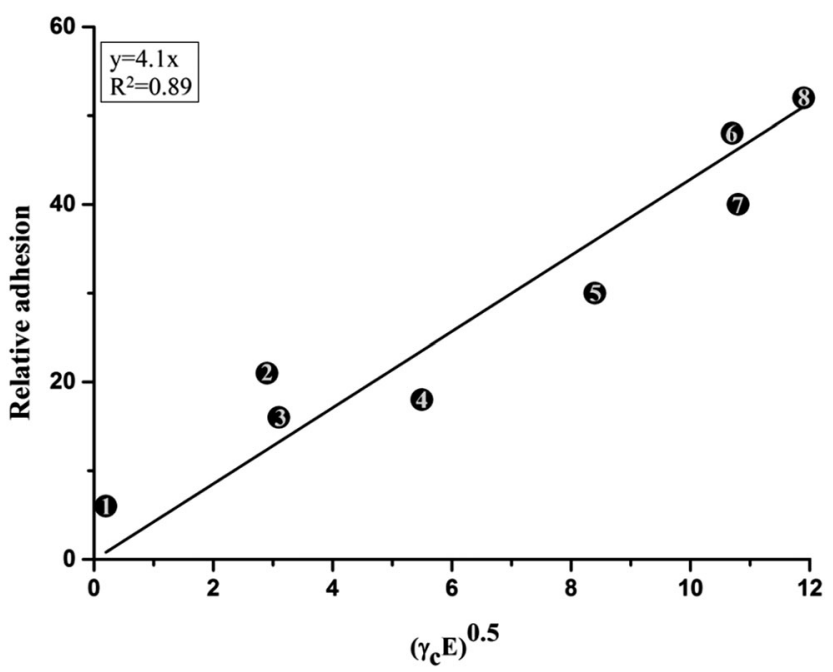

Fig. 4 The relationship between relative adhesion and the square root of the product of critical surface energy $\gamma_{c}$ and $E$ modulus for polymers to be used in AF surfaces. Redrawn from data in ref. 46. The inset numbers correspond to the polymers listed in Table 1.

- A surface which is smooth at the molecular level to avoid infiltration of a biological adhesive leading to mechanical interlocking;

- High molecular mobility in the backbone and surfaceactive side chains;

- A thickness which should be optimized with respect to the fracture mechanics of the interface;

- Molecules which combine all of the above factors and are physically and chemically stable for prolonged periods in the marine environment.

Considering the aspects summarized above and the properties described in Table 1, poly(siloxanes) and fluoropolymers are naturally the best candidates to obtain low adhesion strength and good mechanical properties, hence to be used in 'prevention of attachment' AF strategies (Fig. 2d). The following sections are therefore dedicated to the recent results reported for these polymer categories and their use in marine AF applications.

4.1.1. Silicone-based materials. Poly(dimethylsiloxane) (PDMS) based coatings are largely used for AF applications mainly due to their low critical surface energy, nearly absent micro-roughness and low glass transition temperature $T_{\mathrm{g}}$. These properties arise from a particular chemical structure which combines a flexible backbone based on Si-O-Si bonds, 'long' and 'straight' (1.65 and $159^{\circ}$, respectively) as compared with hydrocarbon $\mathrm{C}-\mathrm{C}-\mathrm{C}$ bonds (1.54 $\AA$ and $112^{\circ}$, respectively), ${ }^{48}$ and the low surface energy side groups (typically, $-\mathrm{CH}_{3}$ ). Additionally, the partially ionic (non-directional) nature of the $\mathrm{Si}-\mathrm{O}$ bonds and the alternating divalent groups in the backbone, result in an increased spacing between the corresponding substituent methyl groups (2.99 ̊̊). ${ }^{48}$ Hence, PDMS surfaces show a conformational mobility which allows a close packing of the pendant methyl groups at the interface but are also highly mobile, which reduces the adhesion of marine organisms. ${ }^{48}$

Many types of silicone compounds and formulations are currently commercially available, as comprehensively reviewed by Lejars et al. ${ }^{49}$ The downside of poly(siloxane)-based coatings has been all along their poor adhesion and mechanical properties, which result in easy damaging during routine handling and navigation of ships and vessels, thereby reducing its performance and service lifetime. To improve the adhesion and durability (i.e. mechanical properties) of silicone-based coatings while retaining their exceptional AF properties, many synthetic pathways have been explored, namely, the application of primers to improve adhesion, the incorporation of inorganic fillers and additional antifoulants and the introduction of poly(urethane) (PU) and/or epoxy segments. ${ }^{49}$

Like the majority of coatings, PDMS based formulations have been prepared with fillers, typically inorganic compounds like silica $\left(\mathrm{SiO}_{2}\right)$, calcium carbonate $\left(\mathrm{CaCO}_{3}\right)$, titanium dioxide $\left(\mathrm{TiO}_{2}\right)$, iron oxides or carbon black. These fillers can improve the mechanical properties by providing reinforcement to the elastomeric material. However, most of them also constitute a weak point as they reduce the intrinsic hydrophobicity of the PDMS matrix, leading to biofouling which grows proportionally to the amount of fillers in the formulation. ${ }^{50,51}$ Some interesting results have been achieved by incorporating natural sepiolite nanofibers $\left(\mathrm{Mg}_{4} \mathrm{Si}_{6} \mathrm{O}_{15}(\mathrm{OH})_{2} \cdot 6 \mathrm{H}_{2} \mathrm{O}\right)$ in a commercial formulation (Sylgard 184), which increased the tensile modulus of the material. The AF properties of the reinforced coating are, however, only efficient towards detachment of specific bio-organisms, e.g. towards Ulva zoospores, and less active then the unloaded PDMS formulation towards such as $A$. amphirite larvae. ${ }^{49}$ Low concentration multi-wall carbon nanotube (MWCNT) dispersions were also used. Although they did not improve the mechanical properties of the PDMS bulk material, the initial hydrophobicity was changed. ${ }^{52}$ Surprisingly, an addition of 
only $0.05 \%$ MWCNTs to unfilled PDMS about halved the critical removal stress of adult barnacles for this modified elastomer, ${ }^{52}$ which was explained based on $\mathrm{CH}-\pi$ electronic interactions involving methyl groups of the PDMS, that render the PDMS chains less mobile and reduce the extent of surface reorganization. Although raw materials availability and production costs may be crucial when aiming for large-scale industrial production of AF coatings containing these speciality fillers, the use of these and other potential nanofillers with intrinsic hydrophobicity, such as SWCNT, modified graphite or even graphene, ${ }^{53}$ open new possibilities for extremely efficient and durable silicon-based reinforced AF coatings aiming to employ the 'detachment of biofoulants' strategy.

Another strategy that has been intensively pursued to improve the AF efficiency of silicone-based coatings is the impregnation with fluid low surface energy additives, i.e. oils, which migrate to the air interface and eventually leach, thereby creating weak surface layers that contribute to the detachment of the biofouling. ${ }^{54-56}$ However, in many cases these additives limit even further the service lifetime of the materials, as they weaken the mechanical properties of the coatings by making them more brittle, leading to easy cracking and fouling, as the additives deplete. ${ }^{57}$ Additionally, leaching of silicone-based fluids may not be an elegant, and moreover environmentally questionable, way of providing $\mathrm{AF}$ protection in marine environments.

The design of cross-linked systems based on urethane and epoxy chemistries with a self-stratifying ability, constitutes one of the most promising approaches to develop AF silicon-based coatings with improved mechanical and adhesion properties. In self-stratifying coatings a low surface energy component segregates to the air interface during film formation before it becomes a constituent part of the polymer network (Fig. 5).

Self-stratified cross-linked poly(siloxane)-poly(urethane) (PU) coatings were extensively investigated by Webster and co-workers. ${ }^{58-63}$ The first systems reported by Majundar and Webster $^{58}$ consisted of cross-linked PDMS-PU coatings showing microtopographical surface domains of PDMS on a PU matrix background, spontaneously formed by phase separation during film formation. These coatings showed a significant decrease of the adhesive strength of $A$. amphitrite barnacles ${ }^{59}$ and prompted further studies on a variety of PDMS-PU systems. The best candidates for marine applications were screened by a combinatorial high-throughput approach that investigated the synthesis, formulation and characterization parameters. ${ }^{61}$ For a large set of coatings containing a PDMS backbone and poly(caprolactone) (PCL) blocks (Fig. 6a), Ekin et al. ${ }^{61}$ reported that the surface energy decreased as the percentage of siloxane

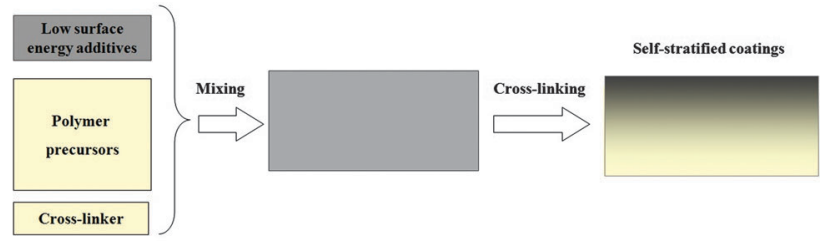

Fig. 5 Schematic of the formation of self-stratifying coatings. polymer was increased (from $\sim 21$ to $\sim 16 \mathrm{mN} \mathrm{m}^{-1}$ ); consequently the pseudo-barnacle adhesion also increased. These results are in accordance with the minimum of the Baier curve. ${ }^{19}$ The increase of the $M_{\mathrm{w}}$ of the PDMS component also reduces the surface energy, rendering the coatings more hydrophobic. This lowered hydrophobicity was maintained even after 30 days of immersion in water. ${ }^{61}$ When di-functional siloxanes were used, the addition of PCL blocks to the siloxane-based backbone increased the adhesion of pseudo-barnacles. Interestingly, the adhesion decreases with tetra-functional siloxane groups.

More recently, Bodkhe et al. ${ }^{63}$ investigated the effect of formulation variables, such as the nature and amount of solvent (e.g. MAK, EEP and butyl acetate), type of polyol and coating application method, on the surface properties of the selfstratified siloxane-PU coatings. Under the optimal conditions, these coatings showed a better biofouling detachment performance when compared to the industrial-reference silicone based coatings, such as Intersleek ${ }^{\circledR}$ and Silastic ${ }^{\circledR}$ T2. ${ }^{64}$ However, the formulation parameters can have a strong influence on the final chemical surface composition, hence, on the fouling detachment ability. For example, the nature and content of solvent have a considerable effect on the solubility and selfstratifying behaviour of the PDMS component. A higher content of a "bad solvent" for PDMS, e.g. EEP, favours the H-bonding interaction with the PU and limits the self-stratification. This resulted in an increase of the coatings roughness which lead to a higher adhesion strength, i.e. lowered the fouling detachment performance of three of the marine organisms tested, namely macroalgae, bacteria and barnacles.

In order to improve the mechanical and adhesion properties of PDMS, the incorporation of poly(urea), epoxy and oxetane segments into the silicone material was also investigated (Fig. 6). Fang et al. ${ }^{65}$ prepared coatings with a PDMS polymer containing polyurea linkages (Fig. 6b), consisting of an interconnected network with hydrogen bonded hard domains which resulted in increased mechanical rigidity. The authors showed that by fine-tuning the extent of phase segregation and the size of the micro- and nano-domains, which resulted in completely different topographic features, a good compromise could be obtained between good mechanical properties and AF detachment performance.

Rath et al. ${ }^{66}$ modified an aliphatic epoxy resin with isocyanatecapped PDMS pre-polymers (Fig. 6c) and prepared coatings by reaction with a polyether diamine (Jeffamine-500) with about 15 to $30 \mathrm{wt} \%$ of PDMS content. The silicone-modified epoxy resins showed a bi-phase morphology and improved thermal stability, as compared to the unmodified resins as well as considerably lower surface energy and roughness due to surface enrichment with silicone moieties. The PDMS-epoxy coatings were immersed in seawater and cleaned with running-hose water to evaluate the biofouling detachment performance. The biofoulants grown after 60 days immersion (slime and settlement of barnacles, oysters, polycheates and ascidines) were much more easily detached from the PDMS-modified coatings then from reference non-modified resins. ${ }^{67}$ After 90 days immersion, however, a residual amount of biofoulants was left even after the washing procedure. 


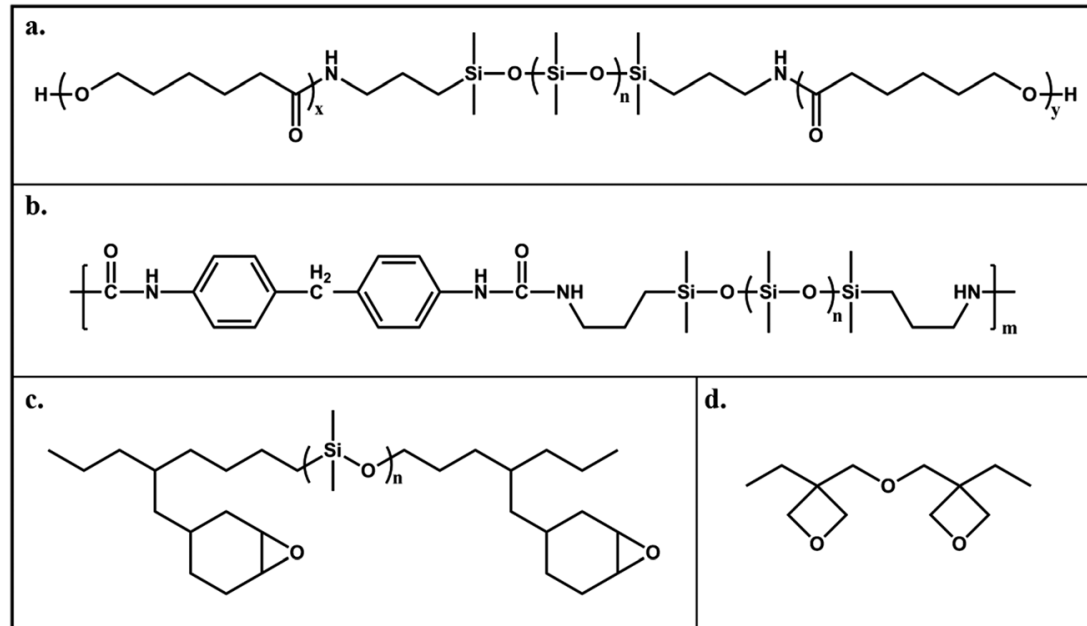

Fig. 6 Examples of typical chemical segments (chemical structures) introduced into PDMS-based formulations or pre-polymers, to improve its mechanical and adhesion properties: (a) Poly(urethane); ${ }^{61}$ (b) poly(urea); ${ }^{65}$ (c) epoxy; ${ }^{66}$ (d) oxetane. ${ }^{68}$

This fact was attributed to the surface reorganization; as water penetrates through the PDMS layer, the hard segments of the ester and urethane moieties migrate to the water interface changing the polymer surface energy and heterogeneity, and consequently the adhesion strength of the bio-organisms increases. ${ }^{67}$

Finally, PDMS-epoxy pre-polymers were toughened by reacting with oxetane units (Fig. 6d) with ultra violet (UV)-initiated cationic photopolymerization. ${ }^{68}$ The coatings containing 10 to $20 \%$ of oxetane showed a higher tensile modulus then the equivalent PDMS-epoxy resins, retained a low surface energy $\left(<15 \mathrm{mN} \mathrm{m}^{-1}\right)$, had a high CA and were stable upon immersion and water-jet washing with no signs of surface rearrangements. Accordingly, their biofoulants detachment performance (for the bacteria H. pacifica, alga Ulva and pseudo- and live A. amphitrite barnacles) was rather good, as compared to commercial silicone formulations.

In addition to the promising results obtained with these materials, UV-cured coatings present advantages such as, fast cure and low volatile organic content (VOC), which are certainly in line with the strict environmental regulations being implemented for marine applications. UV- and LED-photopolymerization technology is experiencing fast developments and adaptations, and it is expected that also in AF marine coating applications, it will become an extremely favorable method as it may result in shorter application times, lower maintenance costs and much lower environmental impact.

Although silicon-based coatings are amongst the most successful AF coatings in the "prevention of attachment" approach, for soft and hard macrofoulants so far, slimes dominated by diatoms are not readily detached from PDMSbased AF surfaces even at high operating speeds, and in this case underwater cleaning is still required. Holland et al. ${ }^{69}$ showed that three different diatom species adhere strongly, as compared to glass, to a hydrophobic PDMS elastomer surface prepared from a silicone-based commercial formulation (Silastic ${ }^{\mathbb{R}}$ T2) resulting in an extensive colonization of the surfaces which were initially designed for easy detachment of biofoulants.
It has been reported that diatoms secrete different types of macromolecules (adhesives), but little is known about the nature of the forces between these adhesives and the surfaces, how they vary between species, and if diatoms can adapt to different surfaces. These facts clearly indicate that an input from biology is necessary if we want to avoid adhesion of specific bio-organisms on synthetic surfaces. However, it seems that the more we know about their complex and adaptable operating modes, the further away is the dream of finding a universal AF material for marine bio-organisms.

As reviewed above, a number of silicone-based systems with improved mechanical and adhesion properties, thus extended durability, have been investigated. However, the majority of these systems rely on the high concentration of silicon-based components in the top layers of the coatings, formed by selfstratification or by phase segregation upon film formation. A final consideration to be made concerns the depletion and leaching of these silicon-based species as the surface wears out, leading to changes in the surface chemical composition (eventually also topography) and lowering of the AF performance. Researchers need to tackle this problem as well, to achieve long durability and high AF performance levels all through the materials life-cycle. One possible solution can be to introduce self-healing strategies in the polymeric materials, such as a selfreplenishing principle ${ }^{70}$ which will allow to recover the surface chemical functionality by replenishing the damaged surfaces with new silicon-based species.

4.1.2. Fluorine-based materials. Fluoropolymers can be used to form non-porous, low critical surface energy films (in the range of $10-20 \mathrm{mN} \mathrm{m}^{-1}$ ) with non-sticking characteristics. This low adhesion on fluoropolymers originates from the exposed $\mathrm{CF}_{3}$ moieties at the interface. The critical surface energy depends strongly on the surface chemical groups and decreases in the following order, $-\mathrm{CH}_{2}\left(36 \mathrm{mN} \mathrm{m}^{-1}\right)>-\mathrm{CH}_{3}$ $\left(30 \mathrm{mN} \mathrm{m}^{-1}\right)>-\mathrm{CF}_{2}\left(23 \mathrm{mN} \mathrm{m}^{-1}\right)>-\mathrm{CF}_{3}\left(15 \mathrm{mN} \mathrm{m}^{-1}\right){ }^{36}$ Hence, the assembly of the perfluoroalkyl groups closely packed on the surface and their permanent cross-linking in 
this arrangement minimizes the surface energy, the surface molecular diffusion and also possible rearrangements when exposed to marine adhesives. The stiffness added by the fluorine atoms results in limited mobility which hinders the rotation around the backbone bonds, hence, molecular rearrangements at the surface are restricted and this leads to less fouling. A higher critical stress is also needed to make the adhesivesubstrate joints fail due to a higher bulk modulus as compared to silicon elastomers. Thus, the biofouling, which does accumulate on the surface, is not easily detached.

Poly(tetrafluoro ethylene) (PTFE) or fluorinated ethylenepropylene copolymers would be the best candidates for $\mathrm{AF}$ applications due their very good resistance towards $\mathrm{pH}$, salinity, UV, temperature and organics (solvents and oils) exposure, but their insolubility in common organic solvents raises many limitations with respect to processing and application on coatings. Moreover, it accumulates very rapidly biofouling due to heterogeneities which enclose microcavities where bioadhesives can penetrate and attach via mechanical interlocking. PTFEfluorinated epoxy and poly(urethane) formulations containing PTFE particulates were investigated as AF materials, ${ }^{71}$ however, the irregularities on the surface prompted the adhesion of barnacles in time, which strongly attached to the surface due to association of the polar groups of the barnacle adhesives to the highly polar carbon-fluorine bond. Very recently, Aizenberg et $a .^{72}$ reported a new approach which takes advantage of the porosity of PTFE substrates to design AF surfaces. The slippery liquid-infused porous surfaces (SLIPS) consist of PTFE porous membranes or microstructured fluoro-silanized substrates, show an outstanding AF performance towards common bacteria when tested for a 7-day period in a continuous flow environment, as compared to current state-of-the-art poly(ethylene glycol) (PEG)modified AF surfaces. This behavior was attributed to the high mobility on the slippery interface, which presents the bacteria with a "smooth and liquid" low energy surface, provided by the infused liquid which is immiscible with the aqueous medium and diffuses out the pores. Although issues with processing PTFE and possible restrictions with respect to the use of freestanding fluorinated-lubricants in marine environments are still a concern, the SLIPS principle remains an interesting approach.

Several other fluorinated polymers have been investigated for marine AF applications and an extensive revision has been provided by Lejars et al. ${ }^{49}$ Amongst these, the most common are fluorinated (meth)acrylates, perfluoropolyethers (PFPE) and poly(ethylene glycol) (PEG) fluoropolymers. The most recent reports in these categories are briefly described here.

Poly(perfluoro(meth)acrylates) were investigated for AF purposes by Tsibouklis and co-workers. ${ }^{73-75}$ The first films were composed from simple perfluorinated poly(methacrylates) with perfluorinated chains of different lengths, and presented low surface energy $\left(<10 \mathrm{mN} \mathrm{m}^{-1}\right)^{73}$ and low settlement of bacteria Pseudomonas, alga Ulva, and barnacle A. amphitrite. ${ }^{74}$ Analogous polymers with two pendant fluoroalkyl-chains also exhibited a low attachment of biofoulants. ${ }^{75}$ Nevertheless, a heavy biofouling (fouling resistance of $-5 \%$ ) was observed on these films after long periods of immersion (over 7 months), which was attributed to the extensive surface reconstruction via reorganization of the surface chemical groups and contributions from the electrondonor (Lewis-base) components. ${ }^{75}$ Schmidt et al. ${ }^{76}$ were able to avoid significantly such surface rearrangements by using a perfluoro(methacrylate)-acrylic acid copolymer cross-linked with a (2-isopropenyl-2-oxazoline)-methacrylate copolymer which also showed a low surface energy $\left(12-17 \mathrm{mN} \mathrm{m}^{-1}\right.$ ) (Fig. 7a). The $-\mathrm{CF}_{3}$ moieties assembled at the interface from the tightly packed perfluoroalkyl groups were immobilized due to the high crosslinking density and tend to resist to induced surface reorientation or biofoulants adhesives infiltration, hence biofoulants could be easily detached.

More recently, Gao et al. ${ }^{77}$ investigated poly(n-alkyl methacrylates) end-capped with 2-perfluorooctyl methacrylates (F-MA), exhibiting ordered structures of the fluorinated-chains which results in different $\mathrm{CF}_{3} / \mathrm{CF}_{2}$ ratios at the top-surface (Fig. 7b). The adsorption of proteins (fibrinogen) at the surface decreased linearly with increasing $\mathrm{CF}_{3} / \mathrm{CF}_{2}$ ratio which was also attributed to the very-close packed array of the $-\mathrm{CF}_{3}$ groups resulting in very low surface energy, hence an extremely high resistance to protein adhesion. One other way to immobilize the perfluoroalky groups is to make use of liquid crystalline alkyl spacers to achieve a better orientation and packing of the fluorinated groups, which can be reached with block copolymers modified with semi-fluorinated side chains linked through an esther $^{78,79}$ (Fig. 7c) or ether bond ${ }^{80}$ (Fig. 7d).

Finally, perfluoro(polyether) (PFPE) polymers have also been intensively investigated for AF coatings using the 'detachment of biofoulants' approach. PFPEs are generally considered to be non-toxic under normal operating conditions and demonstrate a backbone rotation flexibility similar to that of PDMS due to the $\mathrm{C}-\mathrm{O}$ backbone bonds, while offering the low surface energy and a high chemical resistance typical of fluoropolymers.

DeSimone et al. ${ }^{81}$ investigated a series of PFPE-based crosslinkable random terpolymers, obtained via the combination of three monomers: an alkyl (meth)acrylate, a glycidyl methacrylate and a methacryldiamide perfluoropolyether (PFPE) macromonomer. By varying the alkyl moieties, the $T_{\mathrm{g}}$ of the materials could be tuned from $-6{ }^{\circ} \mathrm{C}$ to $125{ }^{\circ} \mathrm{C}$, which allowed to study independently the effect of modulus and $T_{\mathrm{g}}$ on the AF performance. The higher the $T_{\mathrm{g}}$ and the cross-linking of the polymers, the lower the CAH and the extension of surface reconstruction, due to more restricted segmental mobility of the polymer chains, which results in better AF performance. It was also shown that the incorporation of more polar monomers promoted the intermolecular interactions with the aqueous medium, enhancing the driving force for surface segregation of the PFPE domains. The number of spores settled on these cross-linked PFPE-based coatings was less than on PDMS-based standards, and the percentage of removal was greater than for the reference Silastic ${ }^{\mathbb{R}}$ T-2 material, showing their high potential for the detachment of biofouling under suitable hydrodynamic flow conditions.

More recently, UV irradiation has been used to prepare cross-linked coatings from fluorinated polyurethanes ${ }^{82}$ and PFPE-copolymers. ${ }^{83}$ The latter where prepared from di-functional PFPE macromonomers with methacrylate and styrene end-groups 


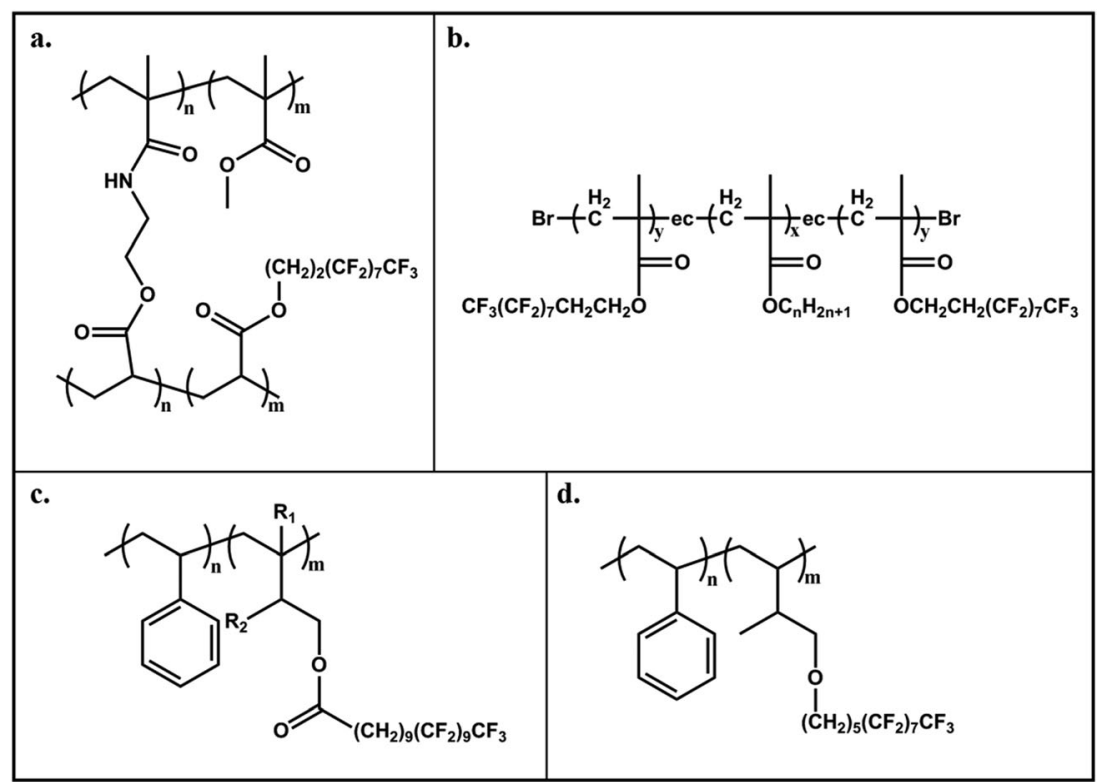

Fig. 7 Examples of perfluoropolymers used for AF surfaces with improved immobilization of the perfluoroalkyl groups, i.e. decreased chances of surface reorganization: (a) Perfluoro(methacrylate)-acrylic acid copolymer cross-linked with (2-isopropenyl-2-oxazoline)-methacrylate copolymer; ${ }^{76}$ (b) poly( $n$-alkyl methacrylates) end-capped with 2-perfluorooctyl methacrylates ${ }^{77}$ and (c) and (d) fluorinated-block-copolymers with semi-fluorinated liquid crystalline side-chains connected by an ester ${ }^{79}$ or ether bond, ${ }^{80}$ respectively.

and exhibited clustered domains of nanometer size of the respective end-groups within the PFPE matrix. By varying the cross-linking density, the Young's modulus of the fully cross-linked PFPE elastomeric film could be tuned from 1.5 to $90 \mathrm{MPa}$ with a critical surface tension of $8.6-16 \mathrm{mN} \mathrm{m}^{-1}$. The films with the lowest surface tension, Young's modulus and contact angle hysteresis, showed decreased zoospore settlement and spores removal performance comparable to PDMS elastomers standard materials.

The ease of fabrication via the (UV) photo-curing process, combined with the ability to tune the bulk and surface properties, and the inert and non-toxic properties of PFPEs, present these systems as highly promising candidates for future applications on fouling-detachment coatings in marine environments.
4.1.3. Combined fluorine-silicon based materials. Within the 'detachment of biofoulants' approach for $\mathrm{AF}$ coatings, a remaining category to be mentioned combines the best of "two worlds", i.e. the low critical surface tension from siliconbased materials and the chain "rigidity" and "dense-packingability" of the fluorinated compounds, which reduces surface rearrangement events.

Perfluoro(polyether) (PFPE) unreactive fluorinated additives or liquid oils (Fomblin Y, Fig. 8a and Fomblin Z, Fig. 8b) were added to standard condensation-curable PDMS formulations, in percentages varying from 2 to $10 \% \mathrm{wt}$, to enhance the $\mathrm{AF}$ properties and stability in water. After 3 months of immersion, the coatings were significantly less fouled then the reference

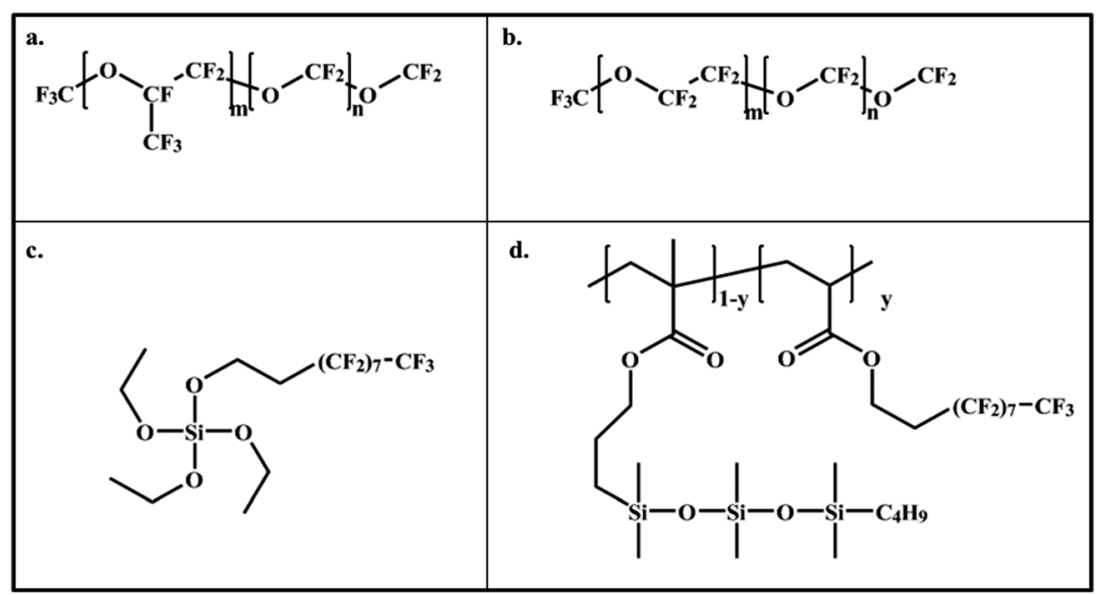

Fig. 8 Examples of silicone-fluorine components for AF coatings: (a) Trifluoromethyl-branched fluorine end-capped PFPE (Fomblin Y); (b) linear diorgano end-capped PFPE (Fomblin Z) (c) (heptadecafluoro-1,1,2,2-tetrahydrodecil)triethoxysilane (fluorinated-TEOS) and (d) copolymer of perfluorinated- and polysiloxane-modified acrylates. ${ }^{84}$ 
silicone formulation. Blends of fluorinated-siloxane acrylic copolymers with a PDMS matrix were also investigated for AF purposes. $^{84}$ The fluorinated copolymers (Fig. 8d) naturally segregated towards the air-coating interface reducing the surface energy of the system without changing significantly its mechanical properties. The copolymers were able to saturate the surface of PDMS blends even at very low loading $(0.3 \mathrm{wt} \%)$ and showed a peculiar surface composition with two distinct species: (i) hydrocarbon $\left(-\mathrm{CH}_{3}\right)$ terminals of siloxane chains and (ii) and fluorinated side chains. This composition was explained by the presence of anchoring loops of the flexible and mobile siloxane chains (exposing the alkyl groups at the interface) and the co-existence of a liquid-crystal like rigid structure of the perfluorinated chain-segments at the top $(\sim 5 \mathrm{~nm})$ surface. ${ }^{84}$ This combination resulted in blended-films with extremely good AF properties with a higher performance for the detachment of Ulva sporelings and barnacles than pure PDMS, and reduced settlement of cyprid barnacles. ${ }^{85}$

In addition to additives and blends, silicon formulations with reactive fluorinated compounds have also been investigated. A fluorinated cross-linker with reactive siloxane-end groups (fluorinated-TEOS) (Fig. 8c) was used to cure a $\alpha, \omega$-dihydroxy PDMS formulation. ${ }^{86}$ The surface of the fluorinated coatings was formed by phase-segregated domains with a fluorinatedsiliceous composition that prevented surface reconstruction, water penetration and hydrolysis of the films when immersed in water. ${ }^{86,87}$ In comparison, the smooth reference PDMS films cured by the typical tetraethylorthosilicate (TEOS) cross-linker showed an increased roughness with cracks and erosion pits on the surface after immersion in water.

In a different approach, Thünemann et al. ${ }^{88}$ used a commercial amino-functionalized polysiloxane mixed with perfluorinated dodecanoic acid which forms complexes with the amine moieties. The rubber-like materials exhibited high repellence to water and oil, due to their extremely low critical surface tension (as low as $6 \mathrm{mN} \mathrm{m}^{-1}$ ), attributed to the enrichment of the surfaces with $-\mathrm{CF}_{3}$ groups. Furthermore, the cross-linking of the formulation is accelerated in the presence of the complex without the need of an additional catalyst. These materials have been suggested has potential candidates for non-toxic AF coatings.

More recently, Martinelli and co-workers ${ }^{89-91}$ reported a series of amphiphilic copolymers which were tested for their AF properties, either as single components or blended with commercial silicon formulations. Block copolymers of polystyrene- $b$-polystyrene carrying an amphiphilic polyoxyethylene-polytetrafluoroethylene chain side-group $^{89}$ and poly(dimethylsiloxane)- $b$-poly(ethyleneglycol)fluoroalkyl modified polystyrene ${ }^{90}$ were prepared with various degrees of polymerization by atom transfer radical polymerization (ATRP). Random copolymers of poly(ethyleneglycol)fluoroalkylacrylate-r-polysiloxane methacrylate were synthesized by radical polymerization. ${ }^{92}$ Amphiphilic systems with block-copolymers rely on the intrinsic tendency of the block to phase-segregate in a controlled morphology at the film surface and typically end up with a predominance of one of the blocks at the top surface, while with random-copolymers the surface may be composed by chemical components of both polymers.
An example of the latter case was reported by Martinelli et al. ${ }^{92}$ The surface segregation of the fluoroalkyl segments of the amphiphilic copolymers was responsible for the enrichment in fluorine within $10 \mathrm{~nm}$ of the coating surface, but also that poly(ethylene glycol) (PEG) segments were concentrated at the polymer air interface. ${ }^{92}$

The presence of different chemistries at the top surface of coatings, i.e., molecular heterogeneity, may be played as an advantage to combine the two approaches "detachment of the biofoulants" and "prevention of attachment" and design new high performance AF surfaces. ${ }^{93}$ Following this idea, amphiphilic materials and PEG-modified compounds will be further discussed in the following section.

\subsection{Prevention of attachment of biofoulants}

Although polysiloxanes and fluoropolymers provide good biofoulant detachment properties and are widely used for marine applications, their disadvantages lead researchers to develop other strategies to prevent the adhesion of marine biofoulants. The most important challenge for the antifouling technology is the diversity of adhesives secreted by sea organisms, as they adhere to the surface with different mechanisms, thus requiring different solutions. However, fouling invariably starts with the formation of the conditioning film - adhesion of proteins -, as described in the introductory section. Surface coverage by both macro- and micro-biofoulants depends on the initial ability of single cells to settle and adhere to the surface. ${ }^{29}$ Hence, developing marine AF coatings applicable to all kinds of adhesive organisms is theoretically possible by preventing adhesion of proteins. Within this line of thought, several AF strategies have been reported following the 'prevention of attachment' of biofoulants approach (Fig. 2d). Hydrophilic compounds have been widely used for this purpose, not only in marine applications but also, and even more commonly, in the biomedical and biotechnology fields. More recently, the use of amphiphilic compounds has also been reported and new strategies based on zwitterionic $^{94}$ and self-assembled monolayers have been explored. In the following sections, the most recent results reported for $\mathrm{AF}$ coatings using these materials are discussed.

4.2.1. PEG-based materials. To date, one of the most common approaches to prevent proteins adhesion and biofoulants settlement via hydrophilic interactions has been the use of poly(ethylene glycol) (PEG) chains attached on chemically modified surfaces. ${ }^{95-99}$ Despite a relatively high surface energy $\left(>43 \mathrm{mN} \mathrm{m}^{-1}\right.$ ), PEGcoated surfaces are known for their resistance to protein adsorption and cell adhesion, and they have also demonstrated resistance to settlement of marine biofouling organisms. ${ }^{78}$ Although the reasons for the resistance to proteins adhesion are not well-proven, there are widely recognized theoretical explanations for this phenomenon. One of these explanations is based on the importance of the interfacial energy between a surface and water. As discussed in the previous section, one of the most commonly used polymers in the "detachment of biofoulants' approach is poly(dimethylsiloxane) (PDMS). PDMS has an interfacial energy with water of about $52 \mathrm{mN} \mathrm{m}^{-1},{ }^{100}$ which is rather high and therefore favors adsorption on the 


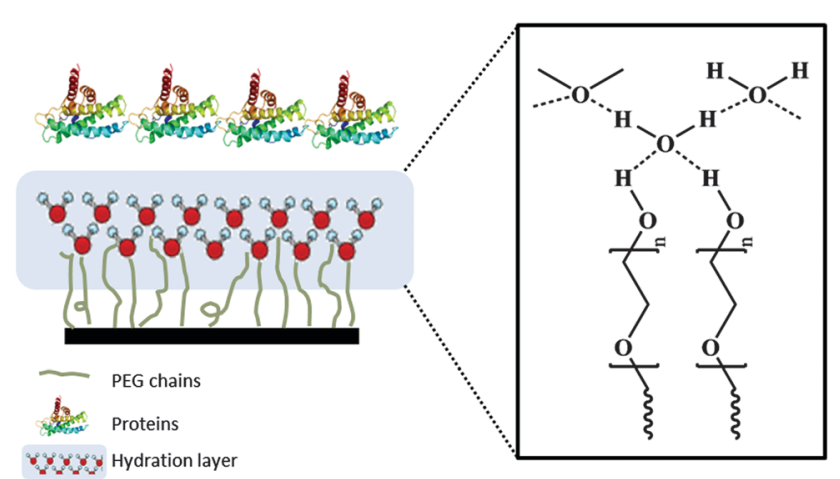

Fig. 9 Schematic representation of preventing the attachment of proteins via the hydration layer derived on PEG chains.

PDMS surface to minimize the interfacial energy. However, the adsorption on hydrophilic surfaces is not easily realized as the interfacial energy with water is quite low. For example, the water interfacial energy of PEG is below $5 \mathrm{mN} \mathrm{m}^{-1} .101$

The second and most accepted explanation for low proteins adhesion is based on the study performed by Jeon et $a l^{95}$ who used hydrophobic surfaces functionalized with PEG-chains to understand the interactions between these surface and proteins. The proteins were modeled as a block of infinite length placed parallel to the surface - perpendicular to the PEG chains (Fig. 9). In this study, two main reasons were put forward to explain the low adhesion of proteins to the PEG-functionalized surface. The first is the repulsive elastic force resulting from the compression of the PEG chains when a protein moves towards the surface while the second is related to the thermodynamically osmotic stress developed, which makes the removal of the water molecules from the strongly hydrated PEG chains very unfavorable.

Heuberger et al. ${ }^{102}$ supported this explanation by showing that the water content inside surface-grafted PEG chains is higher than $80 \mathrm{vol} \%$. This large amount of water leads to a high degree of organization in the PEG-water complex, which is energetically and kinetically unfavorable to disrupt. This study also considered the parameters affecting the magnitude of the elastic and osmotic stresses leading to repulsion of proteins. It was found that the surface density of grafted PEG chains and the PEG chain length have a significant effect on the protein attachment resistance. However, the precise influence of the PEG-grafts molecular weight still finds some controversy amongst researches in the field since in a number of cases, a 'proteinattractive' instead of a 'protein-repulsive' state has been reported for PEG chains. ${ }^{103,104}$

Many different methods have been developed for the immobilization of PEG chains on different substrates to optimize the surface chains density, thus reducing protein adsorption to a minimum and prevent biofoulants attachment. Physisorption, chemisorption and covalent grafting of PEG chains from solution onto different surfaces have been investigated and were able to reduce protein adsorption below the nominal limit of several $\mathrm{mg} \mathrm{cm}^{-2}$ - which is considered to be the approximate limit of detection (LOD) of most label-free interfacial detection techniques. Nevertheless, the immobilization of PEG chains with either of the methods could still not yield the desired high surface chains density, due to the excluded volume effect.

Extensive research has been performed to enhance the surface chain density. Theoretically, a complete coverage of the surface can be achieved if the attachment sites of each PEG chain are at a distance lower than the radius of gyration of PEG in solution. ${ }^{105,106}$ This desired high surface chains density, and thus the formation of a dense and defect-free grafted layer with EG moieties, was investigated by using longer PEG chains, comb-like polymers with PEG-side chains, ${ }^{78}$ PEG-polymer brushes and dendrimers. Benhabbour et al. ${ }^{107}$ for example, used a thiol- and hydroxylterminated PEG (SH-PEG650-OH) post-functionalized with aliphatic polyester dendrons of the first to fourth generations. ${ }^{107}$ The resulting surfaces were tested for both hydrophilicity and protein resistance and showed that, although the dendronization increased the surface hydrophilicity, it also increases protein adsorption. This paradox was explained by means of the chain flexibility. The introduction of dendrons with multiple peripheral - $\mathrm{OH}$ groups hinders the conformational flexibility due to the strong interactions between the terminal $-\mathrm{OH}$ groups and the underlying PEG moieties. The interpretation of these findings discloses that chain flexibility is another important parameter to be considered when designing hydrophilic, protein resistant surfaces for AF purposes.

In summary, several parameters can be tuned to reduce protein adhesion and settlement via using PEG-modified surfaces: (i) the PEG chain length and molecular architecture; (ii) chain density (grafting) and (iii) chain flexibility. It should be noticed, however, that this approach relies very much on the possibility and the efficiency of the surface chemical modification, which on its turn depends strongly on the nature and chemical composition of the substrate to be modified (e.g. reactive groups or initiating sites available at the surface) as well as on the chemical grafting process itself, e.g. specific solvents and temperature conditions required. For many AF applications, such in water membranes, filters and biomedical devices, these surface modification strategies may prove feasible, however, for coatings on vessels or large marine structures this is certainly a limitation. Moreover, such chemically modified surfaces offer little or no robustness with respect to mechanical damage and wear, which is certainly a requirement for most of the marine applications. Hence, several scientific and technological challenges remain to be overcome, in order to fabricate suitable polymer grafts which can resist protein adsorption a: (a) producing strongly adherent end-tethered hydrophilic (PEG) polymer grafts, (b) produce grafts that can be tethered to a variety of homogeneous and heterogeneous surfaces and (c) acquiring accurate control and knowledge over the grafting density and molecular weight of grafted polymers.

4.2.2. Self-assembled monolayers (SAM). Another approach widely investigated in the literature for AF purposes and prevention of 'attachment of biofoulants' is the use of self-assembled monolayers (SAMs) with ethylene glycol (EG) units. Prime et al. ${ }^{108}$ showed that SAMs with only a few EG units per molecule have shown remarkable resistance to protein adsorption. 
Schilp et al. ${ }^{109}$ examined the relation between selectivity of settlement and surface wettability by investigating the resistance to protein adsorption and the adhesion of Ulva spores and diatom cells on a range of hexa(ethylene glycols) $\left(\mathrm{EG}_{6}\right)$ containing alkenethiols with different end-group terminations $\left(-\mathrm{OH}\right.$ and $\left.-\mathrm{C}_{3} \mathrm{H}_{7}\right)$. The study indicated that the number of attached spores increased with an increase in water contact angle from $\mathrm{EG}_{6}-\mathrm{OH}$ to $\mathrm{EG}_{6}-\mathrm{C}_{3} \mathrm{H}_{7}$. However, the percentage of spores removed decreased with increasing hydrophobicity from $\mathrm{EG}_{6}-\mathrm{OH}(57 \%)$ to $\mathrm{EG}_{6}-\mathrm{C}_{3} \mathrm{H}_{7}(32 \%)$. From this study, two facets of the overall process of adhesion were assessed. First, in order to colonize a surface, swimming spores have to recognize that surface as being suitable; a consequence of this is selective settlement on surfaces, namely with specific wettability. Second, having settled on a surface and made the transition to a permanently attached state, the strength of adhesion is also determined by the interfacial properties. Surface wettability affects both of these processes. Hence, the low settlement observed with the SAMs used in these experiments was a consequence of the swimming spores avoiding the hydrophilic surfaces. However, once the biofoulants settle, the hydrophilic surfaces showed increased adhesion strength, thus making their detachment more difficult.

Schilp and co-workers ${ }^{110}$ also investigated the effect of chain length and the amount of bound water in the ethylene glycol moieties on the adhesion of proteins to the EG-based SAMs. Oligo(ethylene glycol) $\left(\mathrm{OEG}_{x} ; x=1-6\right.$ EG units) and poly(ethylene glycol) (PEG; $\left.\bar{M}_{\mathrm{w}}=2000,5000\right)$ were investigated. The results showed that the CAs of OEG SAMs were in the same hydrophilic range $\left(28^{\circ}-34^{\circ}\right)$. However, $\mathrm{OEG}_{1}-\mathrm{OH}$ showed adhesion of both protein and algal cell, whereas $\mathrm{OEG}_{2-6} \mathrm{OH}$ showed almost no adhesion. Lowering the number of EG units caused a decrease in hydration of the SAMs, while the wettability was kept constant. If the number of EG units in the SAM is reduced to one, the hydration energy is no longer strong enough to prevent displacement of hydration water molecules, with the result that adhesion becomes irreversible, i.e. settlement takes place. The authors denote that hydrophilicity alone cannot account for the failure of the $\mathrm{OEG}_{1}-\mathrm{OH}$ SAMs, since they are more hydrophilic than the $\mathrm{EG}_{2-6} \mathrm{OH}$ SAMs $\left(\mathrm{CA}=28^{\circ}\right.$ and $33-34^{\circ}$, respectively). These authors suggest that there should be at least two proton-acceptor oxygen atoms available in the OEG chain, allowing strong hydration bonds in a double hydrogen bridge bonding configuration, leading to the formation of a strong hydration layer.

While an increasing number of EG units improves the surface resistance to settlement for both, SAMs and PEG-modified chains, the influence of the hydroxyl- and the methoxylterminated PEG chains plays a more important role in the adhesion of proteins or algae cell onto SAMs, as compared with PEG-grafted surfaces. ${ }^{109}$ The authors explained this by the high degree of conformational freedom of PEG chains, which allows their end-groups to be buried in the film, in contrast with the crystalline and densely packed OEG SAMs. Together with the favorable protein resistance obtained by using SAMs, these results reinforced the idea that the main reason of the protein resistance, i.e. prevention of attachment, obtained by PEG-chains is the formation of a hydration layer at the hydrophilic surface rather than the steric repulsion mechanism, caused by the extension of the PEG chains.

4.2.3. Other approaches. Despite the fact that PEGylated polymers are amongst the best protein resistant surfaces, PEGbased materials have tendency to auto-oxidize (to form aldehydes and ethers) in the presence of oxygen, are easily damaged and can lose their function upon minor mechanical impacts. Hence, different polymer categories have been investigated for AF purposes. These alternative systems are all based on four important parameters to be considered while designing the $\mathrm{AF}$ coatings within the "prevention of attachment" strategy (Fig. 2d), as stated by Chapman et al. ${ }^{111}$

- The presence of polar functional groups;

- The absence of any net charge;

- The presence of H-bond acceptor groups;

- The absence of H-bond donor groups.

According to the aforementioned criteria, zwitterionic polymers and SAMs were investigated due to their protein resistance. ${ }^{94,112-114}$ Tegoulia et $a .^{115}$ showed that phosphorylcholine zwitterions bind strongly to water, creating a hydration layer that does not allow proteins to adhere to the surface. However, they could not acquire results that are universally acceptable to all the zwitterionic SAMs tested. Matsuura et al. ${ }^{116}$ reported the use of zwitterionic brushes based on carboxybetain possessing AF properties. Even though there are several examples of zwitterionic compounds used to prevent protein adhesion, they have been mostly explored for biomedical and biotechnological applications, while only more recently them have been potentially devised for marine applications ${ }^{94,117-119}$ A recent study by Yang et al. ${ }^{118}$ with pyridine-based zwitterionic surfaces showed significantly improved resistance against a variety of molecular foulants, namely marine bacteria, and improved tolerance to chlorine exposure as compared to acrylate-based analogues. Also Quintana et al. ${ }^{94}$ investigated recently zwitterionic polymeric brushes based on polysulfobetaines with monoblock and diblock architecturethes for AF purposes in marine environments. The authors showed that "protected" zwitterionic brushes, constructed with a hydrophobic anchoring segment (PS, PMMA), may be used in order to increase the brush anchoring point stability and avoid the unwanted enhancement of osmotic stress along the brush backbone, one of the weaknesses of the homopolymeric zwitterionic brush when exposed to marine environments.

Zhang et al. ${ }^{120}$ grafted poly(sulfobetainmethacrylate) (PSBMA) (Fig. 10a) brushes onto glass surfaces which were tested for prevention of adhesion of Ulva spores and sporelings. Small amounts of both were attached to the surface with very low adhesion strength. Even though not common, polysaccharides have also been investigated for marine AF due to their high water affinity. Cao et al. ${ }^{121}$ used three acidic polysaccharides, hyaluronic acid (HA), alginic acid (AA) and pectic acid (PA) (Fig. 10b-d, respectively), to investigate the settlement and adhesion of Ulva spores and barnacles (Balanus Amphitrite). The results showed that the settlement of spores on the AA and HA surfaces was 


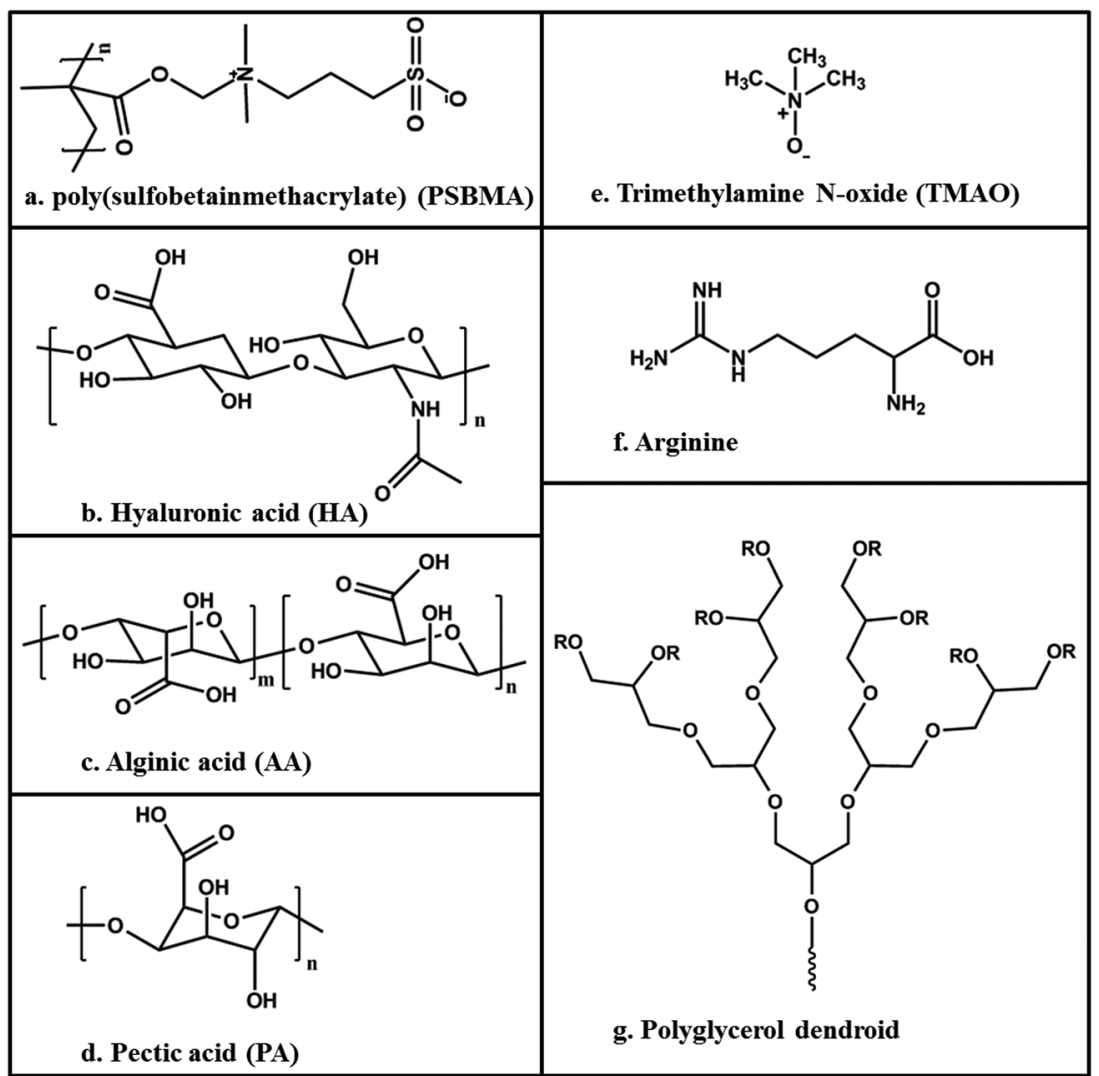

Fig. 10 Chemical structures of: (a) Poly(sulfobetainmethacrylate) (PSBMA); (b) hyaluronic acid (HA); (c) alginic acid (AA); (d) pectic acid (PA); (e) triethylamine $\mathrm{N}$-oxide (TMAO); (f) arginine and (g) polyglycerol dendroid.

only about $10 \%$ as compared to an acid-washed glass surface; however, for the PA treated surface the reduction was to about $75 \%$, still considerably less than for the acid-washed glass surface reference. The adhesion of the barnacles on the HA treated surface was also minimal, hence, the HA modified surfaces showed the best performance for low settlement and easy detachment of both biofoulant species.

The most intriguing question was, however, the contrast between the AF capabilities of the three polysaccharide treated surfaces, as there is no substantial difference between them in hydration ability. Polysaccharide structures are known to bind easily to bivalent ions (like calcium). The authors investigated further the effect of ions on the surfaces by using artificial seawater (salinity of $35 \%$ and total concentration of bivalent cations of $-0.06 \mathrm{~mol} \mathrm{~L}^{-1}$ ).

XPS results showed a reduced tendency of the HA-modified surfaces to complex calcium. The authors state that a lower amount of calcium in the films leads to a reduced adhesion strength, thus a higher rate of detachment of biofoulants. This means that bivalent ions could be the reason for the lower AF performance of the other AA and PA polysaccharide coatings, when used in marine environment. Kerchove et al. ${ }^{122}$ also reported that calcium and magnesium present in alginate films support the growth of a bacterial biofilm. Summing up, this makes polysaccharides poor candidate for AF marine coatings, in spite of their good protein-resistant properties.
Another approach is using nonionic kosmotropes, as they have no net charge but are very soluble and become highly hydrated. Kane et al. ${ }^{123}$ suggested that kosmotropicity has a strong correlation with the protein resistance property of a substrate. This hypothesis was reinforced by Dilly et al. ${ }^{124}$ who reported surfaces that resist to nonspecific protein adsorption by using trimethylamine $N$-oxide (TMAO) (Fig. 10e) grafted to a polymeric support. The authors argue that the reason for the protein resistance is that TMAO forms strong hydrogen bonds with water, leading to the ordering of the water molecules near the substrate. Peptide and peptoid based surfaces, glycerol and carbohydrate derivatives have also been used to design protein-resistance surfaces based on this same principle. ${ }^{125}$

Ederth et al. ${ }^{126}$ investigated the interactions of Ulva spores with Arginine-rich (Fig. 10f) oligopeptide monolayers, as the peptide chemistry allows great flexibility and simple production processes. The structures used in the study - surface tethered peptides - are inspired by antimicrobial peptides of the innate immune system of both, animals and plants, which typically have cationic lysine or arginine residues. The purpose of this study was to test whether the thickness of a SAM or the number of arginine residues on each peptide was relevant, thus understanding if the interaction between the biofoulants and the surface is a nonspecific interaction with a SAM of a particular chemistry, and if the primary structure of the peptide is critical. The study revealed that the position and configuration as well as 
the number of arginine residues in the peptide significantly influence the settlement density of Ulva spores. The simple presence of arginine amino acids in the peptides induces the adhesion of spores and an increased length of the peptide induces a higher number of attached spores, irrespectively of the peptide primary structure.

Finally, Wyszogrodzka and Haag ${ }^{127}$ used polyglycerol dendroids (Fig. 10g) in designing a protein-resistant surface. They worked with both, hydroxyl-terminated and methylated-polyglycols. They concluded that methylation of all-terminal hydroxyl groups resulted in a significant improvement in protein resistance. This deduction is compatible with the parameters stated above by Chapman et al. ${ }^{111}$ as the methylation dissipates the $\mathrm{H}$-bond donor groups. Furthermore, they suggested that the elimination of hydrogen bond donors by methylation increased the mobility and flexibility of individual molecules on the surface.

Although the alternative approaches reported in this section seem rather attractive and promising, mainly in terms of resistance to protein adhesion, most of them have yet to be further and fully investigated for AF marine applications, especially in the context of change in surface properties when in contact for prolonged time with artificial - and eventually natural - seawater and diverse biofoulants.

\subsection{Recent and future approaches}

4.3.1. Amphiphilic approach. Amphiphilic coatings having both, hydrophobic and hydrophilic domains, have been explored as having a combination of both, 'fouling detachment' and protein resistance ('prevention of attachment') approaches, in one single material with enhanced AF properties. ${ }^{128}$

FreijLarson et al. ${ }^{129}$ investigated the adsorption behavior of amphiphilic polymers on a model surface and the effects of these polymers on the adsorption of some proteins. The study involves four different amphiphilic graft and block copolymers containing PEO as the hydrophilic component, adsorbed on a hydrophobic methylated silica surface (HMS). The hydrophobic components comprise: (i) block copolymers containing polyethylenoxide (PEO) of different molecular weights, (ii) a graft copolymer with a backbone of poly(methyl methacrylate-coethylhexyl methacrylate) (Acry) and (iii) two graft copolymers of poly(styrene-co-acrylamide) (Sty1 and Sty2). ${ }^{129}$ The wettability of the surfaces was evaluated by water contact angle (CA) measurements and the results are shown in Table 2.

Both, the advancing and receding water contact angles decreased approximately to the same extent for all the modified surfaces. More importantly, significant higher hysteresis values were obtained for the modified surfaces in contrast to the unmodified HMS surface. This is believed to be due to the relaxation of the hydrophilic and hydrophobic groups or segments at the surface in wet and dry states, respectively. The protein resistance was evaluated on surfaces directly exposed to solutions of the serum proteins fibrinogen $(\mathrm{Fg})$ and human serum albumin (HSA) using ellipsometry to study the adsorption and desorption processes.

A significant difference was observed for the adsorption values of proteins on the Acry-, PE94-modified surfaces as
Table 2 Results of water contact angle and protein resistance measurements on hydrophobic methylated silica surfaces (HMS) modified with different end-groups

\begin{tabular}{lrrll}
\hline Polymer & $\theta_{\text {adv }} / \theta_{\text {rec }}\left(^{\circ}\right)$ & Hysteresis $\left(^{\circ}\right)$ & $\begin{array}{l}\text { Fg adsorbed } \\
\left(\mathrm{mg} \mathrm{m}^{-2}\right)\end{array}$ & $\begin{array}{l}\text { HSA adsorbed } \\
\left(\mathrm{mg} \mathrm{m}^{-2}\right)\end{array}$ \\
\hline HMS & $100 / 97$ & 4 & 4.33 & 1.54 \\
HMS/Acry $^{a}$ & $90 / 55$ & 35 & 0.14 & 0.14 \\
HMS/PE94 $^{a}$ & $95 / 65$ & 30 & 0.12 & 0.05 \\
HMS/Sty1 $^{a}$ & $95 / 56$ & 39 & 1.09 & 0.65 \\
HMS/Sty2 $^{a}$ & $95 / 61$ & 35 & 1.63 & 0.69
\end{tabular}

${ }^{a}$ HMS modifications: acry = graft copolymer with a backbone of poly(methyl methacrylate-co-ethylhexyl methacrylate); PE49 = block copolymer containing polyethylenoxide; Sty1 and Sty2 = two graft copolymers with a poly(styrene-coacrylamide)styrene; $\mathrm{Fg}=$ serum proteins fibrinogen; HAS $=$ human serum albumin. ${ }^{129}$

compared with the Sty-modified HMS (see Table 2). The low protein adsorption on the Acry-modified surface was attributed to the higher amount of PEO grafts exposed at the surface. In an aqueous medium these PEO segments become highly hydrated extending into the solution and sterically preventing the proteins from closely approaching the hydrophobic surface.

Krishnan et al. ${ }^{130}$ investigated the AF properties of comblike block copolymers with amphiphilic side chains (Fig. 11a) on the surface of a polystyrene base. The combination of PEG (hydrophilic) and fluoroalkyl units (hydrophobic) for the amphiphilic side chains was motivated by the initial experiments with two biofoulant species: diatoms showed a higher detachment from surfaces of polymers with PEG side chains as compared to that with semi-fluorinated side chains whereas Ulva sporelings showed the opposite behavior.

The advancing and receding water contact angles reported for these materials were $94^{\circ}$ and $34^{\circ}$, respectively. Also in this case a large hysteresis value was reported, which is consistent with the surface rearrangements argument by FreijLarsson et al. ${ }^{129}$ The surface reconstruction was further investigated by immersing the surfaces in water and performing captive-airbubble contact angle (CA) measurements immediately after 1 day and after 3 days immersion. The CA decreased from $55^{\circ}$ to $46^{\circ}$ (after 1 day) and $41^{\circ}$ (after 3 days), reaching an

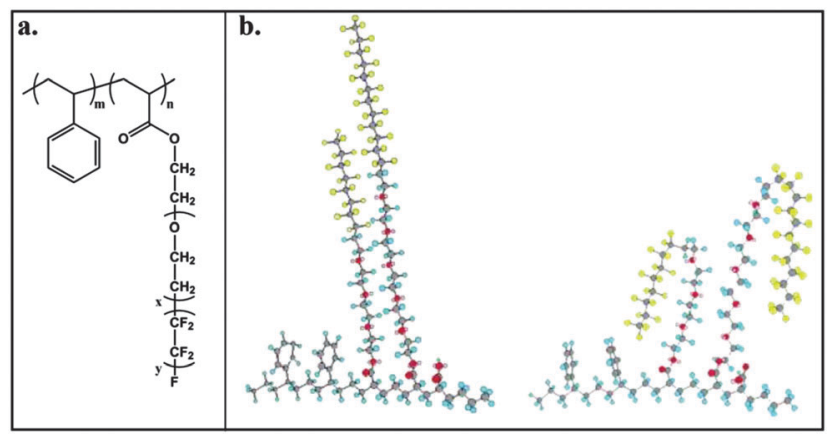

Fig. 11 (a) Chemical structure of comblike block copolymer with amphiphilic side chains and (b) proposed mechanism for surface reorganization of the ethoxylated fluoroalkyl side chains upon immersion of the surface in water. Reproduced with permission from ref. 130. Copyright 2006, American Chemical Society. 
equilibrium value of $31^{\circ}$ after 2 weeks. This decrease in the water CA was attributed to the migration of the PEG segments to the water-polymer interface. Krishnan et al. ${ }^{130}$ pointed out that the surface reorganization corresponding to the rate of addition and retraction of the water droplet in the dynamic CA measurements (typically some 30-60 seconds) and the rearrangements identified by the drop of the CA after 2 weeks immersion time are not related, thus should have different mechanisms. The faster process is possibly due to reorientation of the side chains, as shown in (Fig. 11b), whereas the slower process is due to the diffusion of the polystyrene block towards the interior of the polymer coating, and the surface-active block towards the polymer-water interface.

The copolymers reported by Krishnan et al. ${ }^{130}$ were also tested for marine AF properties by using Ulva spores and Navicula (diatom). The values of settlement and percent detachment after exposure to a shear stress of $53 \mathrm{~Pa}$ in a water channel were compared with a reference PDMS surface. The settlement and strengths of attachment of Ulva spores on the amphiphilic surfaces was comparable to that on PDMS. This led the authors to conclude that the surface became hydrophobic by exposing the fluoroalkyl groups when in contact with Ulva, thus the surface acts as a fouling-detachment coating. On the other hand, the density of the Navicula diatom attached to the amphiphilic surface was around $80 \%$ of the settlement density on the PDMS surface. The attachment strength was also lower on the amphiphilic surface compared to PDMS, with $81 \%$ and $11 \%$ removal, respectively. The high removal of Navicula from the amphiphilic surface was explained by the surface rearrangement which exposes the hydrophilic PEGylated segments when immersed in water, resulting in weak adhesion of the Navicula species. This study proved that the surface rearrangement of amphiphilic surfaces may improve the AF capability of coatings by enhancing the applicability to various species. The additional advantage of this specific system is that any change in surface polarity would occur uniformly throughout the surface, as the surface is covered with a thin layer of the ethoxylated fluoroalkyl side chains.

Surface reorganization is, in fact, a very well know and extensively studied phenomenon in functional polymer surfaces, ${ }^{131,132}$ which may have direct consequences, and not necessarily negative, on the AF properties of the polymer surfaces. Recently, we have also reported a simple method, ${ }^{133}$ DRCA - dynamic recovery contact angle measurements - to determine the time-frames involved in the surface rearrangements on different polymeric surfaces with low surface energy, which can indeed occur at very different time-frames (from a few minutes to hours), depending on the chemical nature and molecular characteristics of the polymer segments at the film surface. This method is rather simple and versatile and may help other researchers to assess the effect of surface rearrangements on a variety of surfaces and eventually take advantage of it to improve the AF performance.

4.3.2. Topographic approach. Topography has been shown to be determinant in the marine fouling area since the surface roughness has a pronounced effect on the wettability of surfaces. Roughness can be defined in different scales: macro(around $10 \mu \mathrm{m}$ ), micro- (around $1 \mu \mathrm{m}$ ) and nano-roughness $(<1 \mu \mathrm{m}){ }^{134}$ Macro-roughness is relatively unimportant for AF surfaces, as the scale is much larger than the typical size of the microorganism cells. However, microtopography plays an important role on biofouling. Surface roughness is considered to enhance adhesive contact, provide protection from hydrodynamic forces, grazing activity and desiccation. ${ }^{135}$

Callow et al. ${ }^{136}$ published a study that quantifies the attachment and spatial relationship of Enteromorpha zoospores with polydimethylsiloxane elastomer (PDMS) surfaces with defined microtopographies. The topographic features in this study were based on two designs: (1) a series of 5 or $1.5 \mathrm{~mm}$ deep valleys with valley floors and ridges varying between 5 and $20 \mu \mathrm{m}$ and (2) pillars of $5 \mu \mathrm{m}$ diameter and 5 or $1.5 \mu \mathrm{m}$ height, spaced 5-20 $\mu \mathrm{m}$ apart.

These designs were selected to demonstrate a spacing that would challenge the settlement of the spores, both physically and chemically. For that purpose, an un-patterned PDMS elastomer was used as a control surface. The authors observed that the spores settled preferentially in valleys and against pillars, especially when the features were down to $5 \mu \mathrm{m}$ deep (the same dimension as the diameter of the settled spore). Moreover, spores favorably settled on the pillars sides. This behavior was explained by the use of work of adhesion. The authors ${ }^{136}$ explained the relation between the change in surface area and adhesion using a simple model of a flat and a grooved surface, as shown in Fig. 12. Upon attachment of a 'sphere' to the flat portion of a substratum, the increase in surface area is equal to the area of the sphere minus the area of contact between the sphere and the surface. Hence, the expansion of the total surface area requires an increase in work or energy exerted on the total system. The sphere, which settles into the valley, has more contact points with the walls and floor of the valley and therefore, requires less energy to settle. In this case the radius of the sphere is equal to the radius of the valley and there are at least two points of contact between the sphere and the surface. Regarding this concept, Callow et al. ${ }^{136}$ concluded that adhesion of 'spheres' can be reduced if the width of the valley is less than twice the radius of the sphere, as the contacts with the surface become point contacts and hence require the most energy/work to settle.

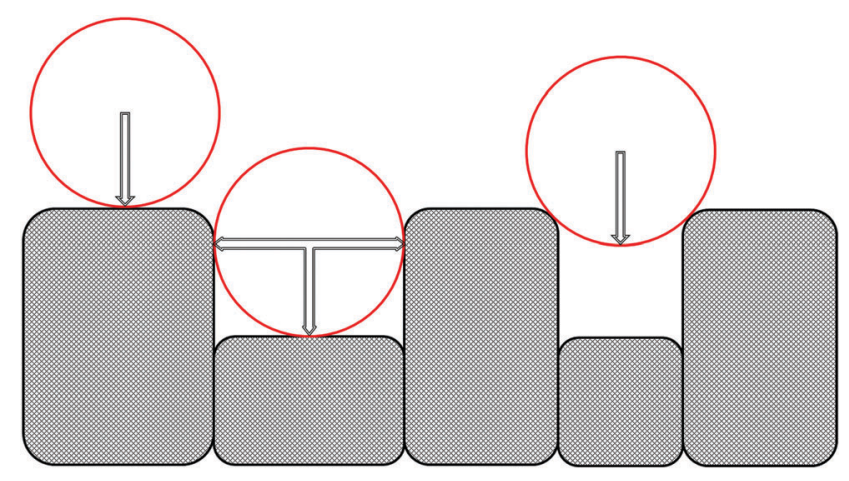

Fig. 12 Schematic 'model' representing the spore adhesion to different surface features. Adapted from ref. 136. 
Carman et al. ${ }^{137}$ used engineered pillars, ridges and a biomimetic topography inspired by the skin of fast moving sharks, replicated in PDMS. The features tested in this study were inspired by the slippery and immaculate un-fouled skin of the shark and included: (a) channels, ridges, pillars, and pits of $5 \mu \mathrm{m}$ wide and spaced 5, 10 and $20 \mu \mathrm{m}$ apart; and (b) ribs of $2 \mu \mathrm{m}$ wide, lengths ranging from 4-16 $\mu \mathrm{m}$, spaced $2 \mu \mathrm{m}$ apart. The topographical surfaces were evaluated for wettability and settlement of Ulva spores. The researchers reported that topography increased the water contact angles up to $20 \%$ for rib patterns, whereas the $20 \mu \mathrm{m}$ spaced ridges and pits behaved the most like the smooth PDMS elastomer. They also concluded that the ridge patterns enhanced spore settlement up to $150 \%$ for the $5 \mathrm{~mm}$ spaced and $5 \mathrm{~mm}$ high ridges, which is roughly equivalent to the diameter of the 'pear-shaped' swimming Ulva spore. Further in agreement with the results of Callow et al., ${ }^{136}$ the density of settled spores approached that of smooth PDMS elastomers as the spacing increased.

In addition to these studies, Carman et $a l .{ }^{137}$ proved that with feature dimensions smaller than the spore body, the settlement can be reduced with the rib patterns. The authors reported that the spores avoided the $2 \mu \mathrm{m}$ wide channels and were largely confined to defects and slightly wider spaces located between adjacent "sharklet diamonds" which reduced the settlement density by approximately $85 \%$, in relation to smooth PDMS elastomers.

Recently, superhydrophobic surfaces with water contact angle values larger than $150^{\circ}$ have been investigated for potential $\mathrm{AF}$ properties by combining hydrophobic materials and nanoscale roughness. ${ }^{138,139}$ Scardino et al. ${ }^{140}$ tested three superhydrophobic coatings, differing in their chemical composition and architecture, against major fouling species in settlement assays. The coatings were prepared by chemically bonding fumed silica nanoparticles to polysiloxane derivatives. The root mean square roughness (RMS) values recorded with AFM and contact angle values for the coatings are shown in Table 3.

Considering that all the three coatings had very similar CA values, this study made it possible to assess whether superhydrophobicity and roughness ensures AF characteristics to the surface. The settlement assays were performed with different biofoulants: (i) being motile and actively selecting preferred sites for attachment (e.g. Ulva spores); (ii) being subsequently motile and settling passively to preferred settlement sites (e.g. Diatoms) and (iii) being non-motile and having no mechanism to select preferred attachment sites (e.g. Polysiphonia spores).

Table 3 Results of water contact angle (CA) and root mean square roughness (RMS) measurements of superhydrophobic surfaces with single (nano) and dual (nano and micron) scale roughness. Adapted from ref. 140

\begin{tabular}{llll}
\hline & Coating $1^{a}$ & ${\text { Coating } 2^{a}}$ & ${\text { Coating } 3^{a}}^{\circ}$ \\
\hline CA (advancing/receding) & $169^{\circ} / 160^{\circ}$ & $155^{\circ} / 145^{\circ}$ & $169^{\circ} / 160^{\circ}$ \\
RMS (scan rate $5 \mu \mathrm{m})$ & $309 \mathrm{~nm}$ & $482 \mathrm{~nm}$ & $374 \mathrm{~nm}$ \\
RMS (scan rate $20 \mu \mathrm{m})$ & $1117 \mathrm{~nm}$ & $1463 \mathrm{~nm}$ & $607 \mathrm{~nm}$
\end{tabular}

${ }^{a}$ Coatings 1 and 2 had dual-scale roughness: nanoscale superimposed on microscale roughness, while Coating 3 had only nanoscale roughness.
The resulting settlement proportions differed significantly according to the biofoulant for coating 1 and 2 with nanoroughness superimposed on microroughness. It was seen that some biofoulants even preferred the coated surfaces over glass. Hence, no generalization could be made for the superhydrophobic surfaces due to this variation of settlement. However, all the biofoulant species including the ones that prefer to attach to hydrophobic surfaces avoided coating 3 (with only nanoroughness) at high levels of significance. From these outcomes, the authors concluded that with respect to roughness and topography there are factors, other than superhydrophobicity, which play a significant role in the AF performance of surfaces. The important parameters responsible for a broad-spectrum fouling resistance were proposed to be as follows:

- The length scale of the coating roughness;

- The percentage of air incursions entrapped at the interface;

- The capability of the coating to hold such entrapped air.

Even though some insight about the effect of topography on the settlement of biofoulants has been devised, ${ }^{141-143}$ much research is needed to combine different chemistries and topographical features to derive AF principles. Gudipati et al. ${ }^{144,145}$ for instance, incorporated a topographical complexity into amphiphilic coatings based on the hypothesis that, if the surface presents optimal nanoscale heterogeneity in terms of composition, morphology and topography, it becomes energetically unfavorable for the biofoulants to adhere via either hydrophobic or hydrophilic interactions, thereby weakening the interactions of the organism with the surface. Glass substrates were functionalized with silane to attach cross-linked hyperbranched fluoropolymer (HBFP)-PEG amphiphilic network coatings. The HBFB-PEG surfaces prepared with different PEG content were investigated for their surface energies, water CA values and protein resistance and compared with control surfaces, functionalized with either HBFB or PEG only. The increasing surface energies proportional to the change in PEG content and high hysteresis of the CA values showed that the PEG chains are mobile in the network and move towards water. The amphiphilic character of the coatings enabled both 'prevention of attachment' (Fig. 2c) and the 'detachment of biofoulants' (Fig. 2c). Furthermore, this study pointed that the compositional and morphological heterogeneity is the key to achieving surfaces that can prevent biofouling.

\section{Final remarks}

AF technologies for marine applications are of large interest mainly due to the economical and environmental benefits. As recent research carried out in the field of non-toxic, nonbiocide-release based AF coatings became more within reach, the future focus is more likely to be on the time-span of the newly developed technologies. While many new coating technologies are still at the proof-of-principle or optimization towards the-utmost-performance level, assessing their performance in real seawater (chemical, temperature and pressure) conditions and marine usage time-frames will clearly define the 
most promising "green" candidates amongst the exciting range of possibilities for AF coatings as described in this review.

Furthermore, the use of new technologies which can provide fast and efficient curing procedures for marine coatings, such as the latest developments on photo-curing (UV-LED or even day-light curing), will allow us to work with low volatile organic content (VOC) formulations, which are in line with the current strict marine policies, with the additional benefit of shorter application times, lower maintenance costs, hence, a much lower environmental impact.

Besides the utmost performance of the AF functionalities, the reduction of the frequency of dry-docking maintenance and repair processes, which are time-consuming and costly, should certainly be addressed as well. For the purpose of increasing the life-span and enhancing the AF functionality versus the unavoidable occurrence of abrasion and wear of the coated surfaces, the most desired breakthrough may come from the combination of AF functionality with self-healing properties, which can automatically self-repair the AF character. ${ }^{146,147}$ The contribution of self-healing mechanisms will bring high performance levels with a longer lifetime to the AF coatings, which will be inevitably exposed to damage.

\section{Abbreviations}

$\begin{array}{ll}\text { AA } & \text { Alginic acid } \\ \text { AF } & \text { Antifouling } \\ \text { CA } & \text { Contact angle } \\ \text { CAH } & \text { Contact angle hysteresis } \\ \text { CDP } & \text { Controlled depletion paint } \\ \gamma_{\mathrm{c}} & \text { Critical surface free energy } \\ E & \text { Elastic modulus } \\ \text { EEP } & \text { Ethyl ethoxy propionate } \\ \text { Fg } & \text { Fibrinogen } \\ \text { FMA } & \text { 2-Perfluorooctyl methacrylate } \\ \text { HA } & \text { Hyaluronic acid } \\ \text { HMS } & \text { Hydrophobic methylated silica } \\ \text { HSA } & \text { Human serum albumin } \\ \text { LOD } & \text { Limit of detection } \\ \text { MAK } & \text { Methyl } N \text {-amyl ketone } \\ M_{\mathrm{w}} & \text { Average molecular weight } \\ \text { PA } & \text { Pectic acid } \\ \text { PCL } & \text { Polycaprolactone } \\ \text { PDMS } & \text { Polydimethylsiloxane } \\ \text { PEG } & \text { Poly(ethylene glycol) } \\ \text { PTFE } & \text { Poly(tetrafluoroethylene) } \\ \text { PFPE } & \text { Poly(fluoropolyether) } \\ \text { PU } & \text { Poly(urethane) } \\ \text { PSBMA } & \text { Poly(sulfobetainmethacrylate) } \\ \text { SAM } & \text { Self-assembled monolayers } \\ \text { SPC } & \text { Self-polishing copolymers } \\ \text { TBT } & \text { Tributyltin } \\ \text { TEOS } & \text { Tetraethyl orthosilicate } \\ \text { TMAO } & \text { Trimethylamine } N \text {-oxide } \\ \text { XPS } & \text { X-ray photoelectron spectroscopy } \\ & \end{array}$

\section{Acknowledgements}

The authors thank the Ministry of Economic Affairs, Agriculture and Innovation via the IOP Self Healing Materials programme (project \# SHM012044) for funding and Ing. Leo van der Ven (AkzoNobel, Sassenheim, NL) and Prof. Rolf van Benthem (DSM Ahead, Geleen, NL) for useful discussion.

\section{References}

1 S. Abarzua and S. Jakubowski, Biotechnological investigation for the prevention of biofouling. biological and biochemical principles for the prevention of biofouling, Mar. Ecol.: Prog. Ser., 1995, 123, 301-312.

2 H. H. Tuson and D. B. Weibel, Bacteria-surface interactions, Soft Matter, 2013, 9, 4368-4380.

3 J. P. Marechal and C. Hellio, Challenges for the development of new non-toxic antifouling solutions, Int. J. Mol. Sci., 2009, 10, 4623-4637.

4 M. P. Schultz, Effects of coating roughness and biofouling on ship resistance and powering, Biofouling, 2007, 23, 331-341.

5 S. M. Evans, T. Leksono and P. D. Mckinnell, Tributyltin pollution - a diminishing problem following legislation limiting the use of Tbt-based anti-fouling paints, Mar. Pollut. Bull., 1995, 30, 14-21.

$6 \mathrm{~J}$. Strand and J. A. Jacobsen, Accumulation and trophic transfer of organotins in a marine food web from the Danish coastal waters, Sci. Total Environ., 2005, 350, 72-85.

7 A. Abbott, P. D. Abel, D. W. Arnold and A. Milne, Cost-benefit analysis of the use of TBT: the case for a treatment approach, Sci. Total Environ., 2000, 258, 5-19.

8 D. M. Yebra, S. Kiil and K. Dam-Johansen, Antifouling technology - past, present and future steps towards efficient and environmentally friendly antifouling coatings, Prog. Org. Coat., 2004, 50, 75-104.

9 M. Candries, M. Atlar, E. Mesbahi and K. Pazouki, The measurement of the drag characteristics of tin-free selfpolishing co-polymers and fouling release coatings using a rotor apparatus, Biofouling, 2003, 19, 27-36.

10 D. M. Yebra, S. Kiil, K. Dam-Johansen and C. Weinell, Reaction rate estimation of controlled-release antifouling paint binders: Rosin-based systems, Prog. Org. Coat., 2005, 53, 256-275.

11 L. D. Chambers, K. R. Stokes, F. C. Walsh and R. J. K. Wood, Modern approaches to marine antifouling coatings, Surf. Coat. Technol., 2006, 201, 3642-3652.

12 J. A. Callow and M. E. Callow, The spore adhesive system of Ulva, Phycologia, 2005, 44, 15.

$13 \mathrm{M}$. Wahl, Marine epibiosis 1. fouling and antifouling some basic aspects, Mar. Ecol.: Prog. Ser., 1989, 58, 175-189.

14 A. S. Clare, Marine natural product antifoulants: Status and potential, Biofouling, 1996, 9, 211-229.

15 W. J. Yang, K. G. Neoh, E. T. Kang, S. L. M. Teo and D. Rittschof, Polymer brush coatings for combating marine biofouling, Prog. Polym. Sci., 2014, 39, 1017-1042. 
16 C. M. Magin, S. P. Cooper and A. B. Brennan, Non-toxic antifouling strategies, Mater. Today, 2010, 13, 36-44.

17 J. E. Gittens, T. J. Smith, R. Suleiman and R. Akid, Current and emerging environmentally-friendly systems for fouling control in the marine environment, Biotechnol. Adv., 2013, 31, 1738-1753.

18 L. Delauney, C. Compere and M. Lehaitre, Biofouling protection for marine environmental sensors, Ocean Sci., 2010, 6, 503-511.

19 R. E. Baier, Surface behaviour of biomaterials: The theta surface for biocompatibility, J. Mater. Sci.: Mater. Med., 2006, 17, 1057-1062.

20 R. E. Baier, Role of Surface-Energy in Thrombogenesis, Bull. N. Y. Acad. Med., 1972, 48, 257-272.

21 D. W. Goupil, V. A. Depalma and R. E. Baier, Prospects for Nontoxic Fouling-resistant Paints, Proc. Marine Industries: Problems and Oppotunities, 1973, vol. 9, pp. 445-458.

22 R. E. Baier, V. A. Depalma, D. W. Goupil and E. Cohen, Human-platelet spreading on substrata of known surfacechemistry, J. Biomed. Mater. Res., 1985, 19, 1157-1167.

23 R. E. Baier, A challenging anomaly - Glass that does not clot blood, GlassResearcher, 2002, 12, 23-24.

24 S. C. Dexter, Influence of substratum critical surfacetension on bacterial adhesion - insitu studies, J. Colloid Interface Sci., 1979, 70, 346-354.

25 Q. Zhao, S. Wang and H. Muller-Steinhagen, Tailored surface free energy of membrane diffusers to minimize microbial adhesion, Appl. Surf. Sci., 2004, 230, 371-378.

26 J. A. Finlay, S. M. Bennett, L. H. Brewer, A. Sokolova, G. Clay, N. Gunari, A. E. Meyer, G. C. Walker, D. E. Wendt, M. E. Callow, J. A. Callow and M. R. Detty, Barnacle settlement and the adhesion of protein and diatom microfouling to xerogel films with varying surface energy and water wettability, Biofouling, 2010, 26, 657-666.

27 T. Vladkova, Surface engineering for non-toxic biofouling control, J. Univ. Chem. Technol. Metall., 2007, 42, 239-256.

28 L. K. Ista, H. Y. Fan, O. Baca and G. P. Lopez, Attachment of bacteria to model solid surfaces: Oligo(ethylene glycol) surfaces inhibit bacterial attachment, FEMS Microbiol. Lett., 1996, 142, 59-63.

29 L. K. Ista, M. E. Callow, J. A. Finlay, S. E. Coleman, A. C. Nolasco, R. H. Simons, J. A. Callow and G. P. Lopez, Effect of substratum surface chemistry and surface energy on attachment of marine bacteria and algal spores, Appl. Environ. Microbiol., 2004, 70, 4151-4157.

30 A. Becka and G. Loeb, Ease of removal of barnacles from various polymeric materials, Biotechnol. Bioeng., 1984, 26, 1245-1251.

31 A. Meyer, R. Baier, C. D. Wood, J. Stein, K. Truby, E. Holm, J. Montemarano, C. Kavanagh, B. Nedved, C. Smith, G. Swain and D. Wiebe, Contact angle anomalies indicate that surface-active eluates from silicone coatings inhibit the adhesive mechanisms of fouling organisms, Biofouling, 2006, 22, 411-423.

32 S. C. Dexter, J. D. Sullivan, J. Williams and S. W. Watson, Influence of substrate wettability on attachment of marine bacteria to various surfaces, Appl. Microbiol., 1975, 30, 298-308.

33 R. J. Good and E. Elbing, Generalization of Theory for Estimation of Interfacial Energies, Ind. Eng. Chem., 1970, 62, 54-78.

34 M. E. Schrader, On adhesion of biological substances to low-energy solid-surfaces, J. Colloid Interface Sci., 1982, 88, 296-297.

35 F. M. Fowkes, Attractive Forces at Interfaces, Ind. Eng. Chem., 1964, 56, 40-52.

36 E. G. Shafrin and W. A. Zisman, Critical surface tension for spreading on a liquid substrate, J. Phys. Chem., 1967, 71, 1309-1316.

37 C. J. Vanoss, R. J. Good and M. K. Chaudhury, The Role of Vanderwaals Forces and Hydrogen-Bonds in Hydrophobic Interactions between Bio-Polymers and Low-Energy Surfaces, J. Colloid Interface Sci., 1986, 111, 378-390.

38 Y. Cui and W. Q. Yuan, Thermodynamic modeling of algal cell-solid substrate interactions, Appl. Energy, 2013, 112, 485-492.

39 C. Liu and Q. Zhao, The CQ ratio of surface energy components influences adhesion and removal of fouling bacteria, Biofouling, 2011, 27, 275-285.

40 Y. Li, Y. H. Gao, X. S. Li, J. Y. Yang and G. H. Que, Influence of surface free energy on the adhesion of marine benthic diatom Nitzschia closterium MMDL533, Colloids Surf., B, 2010, 75, 550-556.

41 D. Y. Kwok and A. W. Neumann, Contact angle measurement and contact angle interpretation, Adv. Colloid Interface Sci., 1999, 81, 167-249.

42 J. K. Spelt, D. R. Absolom and A. W. Neumann, SolidSurface Tension - the Interpretation of Contact Angles by the Equation of State Approach and the Theory of SurfaceTension Components, Langmuir, 1986, 2, 620-625.

$43 \mathrm{~J}$. Lyklema, The surface tension of pure liquids - Thermodynamic components and corresponding states, Colloids Surf., A, 1999, 156, 413-421.

44 M. Hermansson, The DLVO theory in microbial adhesion, Colloids Surf., B, 1999, 14, 105-119.

45 P. C. Hiemenz and R. Rajagopalan, Principles of colloid and surface science, Marcel Dekker, Inc., New York, 3rd edn, 1997.

46 R. F. Brady and I. L. Singer, Mechanical factors favoring release from fouling release coatings, Biofouling, 2000, 15, 73-81.

47 R. L. Townsin and C. D. Anderson, Fouling control coatings using low surface energy, foul release technology, Woodhead Publishing Limited, 2009.

48 R. F. Brady, Properties which influence marine fouling resistance in polymers containing silicon and fluorine, Prog. Org. Coat., 1999, 35, 31-35.

49 M. Lejars, A. Margaillan and C. Bressy, Fouling release coatings: A nontoxic alternative to biocidal antifouling coatings, Chem. Rev., 2012, 112, 4347-4390.

50 H. M. Dalton, J. Stein and P. E. March, A biological assay for detection of heterogeneities in the surface hydrophobicity of polymer coatings exposed to the marine environment, Biofouling, 2000, 15, 83-94. 
51 J. Stein, K. Truby, C. D. Wood, M. Takemori, M. Vallance, G. Swain, C. Kavanagh, B. Kovach, M. Schultz, D. Wiebe, E. Holm, J. Montemarano, D. Wendt, C. Smith and A. Meyer, Structure-property relationships of silicone biofouling-release coatings: Effect of silicone network architecture on pseudobarnacle attachment strengths, Biofouling, 2003, 19, 87-94.

52 A. Beigbeder, P. Degee, S. L. Conlan, R. J. Mutton, A. S. Clare, M. E. Pettitt, M. E. Callow, J. A. Callow and P. Dubois, Preparation and characterisation of siliconebased coatings filled with carbon nanotubes and natural sepiolite and their application as marine fouling-release coatings, Biofouling, 2008, 24, 291-302.

53 J. Rafiee, M. A. Rafiee, Z. Z. Yu and N. Koratkar, Superhydrophobic to Superhydrophilic Wetting Control in Graphene Films, Adv. Mater., 2010, 22, 2151-2154.

54 K. Truby, C. Wood, J. Stein, J. Cella, J. Carpenter, C. Kavanagh, G. Swain, D. Wiebe, D. Lapota, A. Meyer, E. Holm, D. Wendt, C. Smith and J. Montemarano, Evaluation of the performance enhancement of silicone biofouling-release coatings by oil incorporation, Biofouling, 2000, 15, 141-150.

55 C. J. Kavanagh, G. W. Swain, B. S. Kovach, J. Stein, C. Darkangelo-Wood, K. Truby, E. Holm, J. Montemarano, A. Meyer and D. Wiebe, The effects of silicone fluid additives and silicone elastomer matrices on barnacle adhesion strength, Biofouling, 2003, 19, 381-390.

56 J. Stein, K. Truby, C. D. Wood, J. Stein, M. Gardner, G. Swain, C. Kavanagh, B. Kovach, M. Schultz, D. Wiebe, E. Holm, J. Montemarano, D. Wendt, C. Smith and A. Meyer, Silicone foul release coatings: effect of the interaction of oil and coating functionalities on the magnitude of macrofouling attachment strengths, Biofouling, 2003, 19, 71-82.

57 R. F. Brady, A fracture mechanical analysis of fouling release from nontoxic antifouling coatings, Prog. Org. Coat., 2001, 43, 188-192.

58 P. Majumdar and D. C. Webster, Preparation of siloxane Urethane coatings having spontaneously formed stable biphasic microtopographical surfaces, Macromolecules, 2005, 38, 5857-5859.

59 P. Majumdar, S. Stafslien, J. Daniels and D. C. Webster, High throughput combinatorial characterization of thermosetting siloxane-urethane coatings having spontaneously formed microtopographical surfaces, J. Coat. Technol. Res., 2007, 4, 131-138.

60 B. J. Chisholm, S. J. Stafslien, D. A. Christianson, C. Gallagher-Lein, J. W. Daniels, C. Rafferty, L. V. Wal and D. C. Webster, Combinatorial materials research applied to the development of new surface coatings - VIII: Overview of the high-throughput measurement systems developed for a marine coating workflow, Appl. Surf. Sci., 2007, 254, 692-698.

61 A. Ekin, D. C. Webster, J. W. Daniels, S. J. Stafslien, F. Casse, J. A. Callow and M. E. Callow, Synthesis, formulation, and characterization of siloxane-polyurethane coatings for underwater marine applications using combinatorial high-throughput experimentation, J. Coat. Technol. Res., 2007, 4, 435-451.

62 R. J. Pieper, A. Ekin, D. C. Webster, F. Casse, J. A. Callow and M. E. Callow, Combinatorial approach to study the effect of acrylic polyol composition on the properties of crosslinked siloxane-polyurethane fouling-release coatings, J. Coat. Technol. Res., 2007, 4, 453-461.

63 R. B. Bodkhe, S. E. M. Thompson, C. Yehle, N. Cilz, J. Daniels, S. J. Stafslien, M. E. Callow, J. A. Callow and D. C. Webster, The effect of formulation variables on fouling-release performance of stratified siloxane-polyurethane coatings, J. Coat. Technol. Res., 2012, 9, 235-249.

64 B. Watermann, H. D. Berger, H. Sonnichsen and P. Willemsen, Performance and effectiveness of non-stick coatings in seawater, Biofouling, 1997, 11, 101-118.

65 J. Fang, A. Kelarakis, D. Y. Wang, E. P. Giannelis, J. A. Finlay, M. E. Callow and J. A. Callow, Fouling release nanostructured coatings based on PDMS-polyurea segmented copolymers, Polymer, 2010, 51, 2636-2642.

66 S. K. Rath, J. G. Chavan, S. Sasane, A. Srivastava, M. Patri, A. B. Samui, B. C. Chakraborty and S. N. Sawant, Coatings of PDMS-modified epoxy via urethane linkage: Segmental correlation length, phase morphology, thermomechanical and surface behavior, Prog. Org. Coat., 2009, 65, 366-374.

67 S. K. Rath, J. G. Chavan, S. Sasane, Jagannath, M. Patri, A. B. Samui and B. C. Chakraborty, Two component silicone modified epoxy foul release coatings: effect of modulus, surface energy and surface restructuring on pseudobarnacle and macrofouling behavior, Appl. Surf. Sci., 2010, 256, 2440-2446.

68 Z. Chen, B. Chisholm, J. Kim, S. Stafslien, R. Wagner, S. Patel, J. Daniels, L. V. Wal, J. Li, K. Ward, M. Callow, S. Thompson and C. Siripirom, UV-curable, oxetanetoughened epoxy-siloxane coatings for marine foulingrelease coating applications, Polym. Int., 2008, 57, 879-886.

69 R. Holland, T. M. Dugdale, R. Wetherbee, A. B. Brennan, J. A. Finlay, J. A. Callow and M. E. Callow, Adhesion and motility of fouling diatoms on a silicone elastomer, Biofouling, 2004, 20, 323-329.

70 T. Dikic, W. Ming, R. A. T. M. van Benthem, A. C. C. Esteves and G. de With, Self-Replenishing Surfaces, Adv. Mater., 2012, 24, 3701-3704.

71 J. R. Griffith and J. D. Bultman, Fluorinated naval coatings, Ind. Eng. Chem. Prod. Res. Dev., 1978, 17, 8-9.

72 A. K. Epstein, T. S. Wong, R. A. Belisle, E. M. Boggs and J. Aizenberg, Liquid-infused structured surfaces with exceptional anti-biofouling performance, Proc. Natl. Acad. Sci. U. S. A., 2012, 109, 13182-13187.

73 J. Tsibouklis, M. Stone, A. A. Thorpe, P. Graham, T. G. Nevell and R. J. Ewen, Surface energy characteristics of polymer film structures: A further insight into the molecular design requirements, Langmuir, 1999, 15, 7076-7079.

74 J. Tsibouklis, T. G. Nevell and E. Baru, Biofouling-resistant coatings from low-surface-energy polymers, Contact Angle, Wettability and Adhesion, 2006, vol. 4, pp. 461-469.

75 R. A. Pullin, T. G. Nevell and J. Tsibouklis, Surface energy characteristics and marine antifouling performance of 
poly $(1 \mathrm{H}, 1 \mathrm{H}, 2 \mathrm{H}, 2 \mathrm{H}$-perfluorodecanoyl diitaconate) film structures, Mater. Lett., 1999, 39, 142-148.

76 D. L. Schmidt, R. F. Brady, K. Lam, D. C. Schmidt and M. K. Chaudhury, Contact angle hysteresis, adhesion, and marine biofouling, Langmuir, 2004, 20, 2830-2836.

77 J. Gao, D. H. Yan, H. G. Ni, L. Wang, Y. H. Yang and X. P. Wang, Protein-resistance performance enhanced by formation of highly-ordered perfluorinated alkyls on fluorinated polymer surfaces, J. Colloid Interface Sci., 2013, 393, 361-368.

78 S. Krishnan, N. Wang, C. K. Ober, J. A. Finlay, M. E. Callow, J. A. Callow, A. Hexemer, K. E. Sohn, E. J. Kramer and D. A. Fischer, Comparison of the fouling release properties of hydrophobic fluorinated and hydrophilic PEGylated block copolymer surfaces: Attachment strength of the diatom Navicula and the green alga Ulva, Biomacromolecules, 2006, 7, 1449-1462.

79 J. G. Wang, G. P. Mao, C. K. Ober and E. J. Kramer, Liquid crystalline, semifluorinated side group block copolymers with stable low energy surfaces: Synthesis, liquid crystalline structure, and critical surface tension, Macromolecules, 1997, 30, 1906-1914.

80 J. P. Youngblood, L. Andruzzi, C. K. Ober, A. Hexemer, E. J. Kramer, J. A. Callow, J. A. Finlay and M. E. Callow, Coatings based on side-chain ether-linked poly(ethylene glycol) and fluorocarbon polymers for the control of marine biofouling, Biofouling, 2003, 19, 91-98.

81 J. C. Yarbrough, J. P. Rolland, J. M. DeSimone, M. E. Callow, J. A. Finlay and J. A. Callow, Contact angle analysis, surface dynamics, and biofouling characteristics of cross-linkable, random perfluoropolyether-based graft terpolymers, Macromolecules, 2006, 39, 2521-2528.

82 J. M. Park, Y. H. Lee, H. Park and H. D. Kim, Preparation and properties of UV-curable fluorinated polyurethane acrylates, J. Appl. Polym. Sci., 2014, 2014, 890930, DOI: 10.1155/2014/890930.

83 Z. K. Hu, J. A. Finlay, L. Chen, D. E. Betts, M. A. Hillmyer, M. E. Callow, J. A. Callow and J. M. DeSimone, Photochemically cross-linked perfluoropolyether-based elastomers: Synthesis, physical characterization, and biofouling evaluation, Macromolecules, 2009, 42, 6999-7007.

84 J. A. Mielczarski, E. Mielczarski, G. Galli, A. Morelli, E. Martinelli and E. Chiellini, The surface-segregated nanostructure of fluorinated copolymer-poly(dimethylsiloxane) blend films, Langmuir, 2010, 26, 2871-2876.

85 I. Marabotti, A. Morelli, L. M. Orsini, E. Martinelli, G. Galli, E. Chiellini, E. M. Lien, M. E. Pettitt, M. E. Callow, J. A. Callow, S. L. Conlan, R. J. Mutton, A. S. Clare, A. Kocijan, C. Donik and M. Jenko, Fluorinated/siloxane copolymer blends for fouling release: Chemical characterisation and biological evaluation with algae and barnacles, Biofouling, 2009, 25, 481-493.

86 M. Berglin, K. J. Wynne and P. Gatenholm, Fouling-release coatings prepared from alpha, omega-dihydroxypoly(dimethylsiloxane) cross-linked with (heptadecafluoro1,1,2,2-tetrahydrodecyl)triethoxysilane, J. Colloid Interface Sci., 2003, 257, 383-391.
87 E. Johnston, S. Bullock, J. Uilk, P. Gatenholm and K. J. Wynne, Networks from alpha, omega-dihydroxypoly(dimethylsiloxane) and (tridecafluoro-1,1,2,2-tetrahydrooctyl)triethoxysilane: Surface microstructures and surface characterization, Macromolecules, 1999, 32, 8173-8182.

88 A. F. Thünemann and R. H. Kublickas, Low surface energy polysiloxane complexes, J. Mater. Chem., 2001, 11, 381-384.

89 E. Martinelli, S. Agostini, G. Galli, E. Chiellini, A. Glisenti, M. E. Pettitt, M. E. Callow, J. A. Callow, K. Graf and F. W. Bartels, Nanostructured films of amphiphilic fluorinated block copolymers for fouling release application, Langmuir, 2008, 24, 13138-13147.

90 E. Martinelli, M. Suffredini, G. Galli, A. Glisenti, M. E. Pettitt, M. E. Callow, J. A. Callow, D. Williams and G. Lyall, Amphiphilic block copolymer/poly(dimethylsiloxane) (PDMS) blends and nanocomposites for improved fouling-release, Biofouling, 2011, 27, 529-541.

91 E. Martinelli, M. K. Sarvothaman, G. Galli, M. E. Pettitt, M. E. Callow, J. A. Callow, S. L. Conlan, A. S. Clare, A. B. Sugiharto, C. Davies and D. Williams, Poly(dimethyl siloxane) (PDMS) network blends of amphiphilic acrylic copolymers with poly(ethylene glycol)-fluoroalkyl side chains for fouling-release coatings. II. Laboratory assays and field immersion trials, Biofouling, 2012, 28, 571-582.

92 E. Martinelli, M. K. Sarvothaman, M. Alderighi, G. Galli, E. Mielczarski and J. A. Mielczarski, PDMS network blends of amphiphilic acrylic copolymers with poly(ethylene glycol)-fluoroalkyl side chains for fouling-release coatings. I. Chemistry and stability of the film surface, J. Polym. Sci., Part A: Polym. Chem., 2012, 50, 2677-2686.

93 S. H. Baxamusa and K. K. Gleason, Random Copolymer Films with Molecular-Scale Compositional Heterogeneities that Interfere with Protein Adsorption, Adv. Funct. Mater., 2009, 19, 3489-3496.

94 R. Quintana, M. Gosa, D. Janczewski, E. Kutnyanszky and G. J. Vancso, Enhanced Stability of Low Fouling Zwitterionic Polymer Brushes in Seawater with Diblock Architecture, Langmuir, 2013, 29, 10859-10867.

95 S. I. Jeon, J. H. Lee, J. D. Andrade and P. G. Degennes, Protein Surface Interactions in the Presence of Polyethylene Oxide. 1. simplified Theory, J. Colloid Interface Sci., 1991, 142, 149-158.

96 P. Harder, M. Grunze, R. Dahint, G. M. Whitesides and P. E. Laibinis, Molecular conformation in oligo(ethylene glycol)-terminated self-assembled monolayers on gold and silver surfaces determines their ability to resist protein adsorption, J. Phys. Chem. B, 1998, 102, 426-436.

97 A. J. Pertsin and M. Grunze, Computer simulation of water near the surface of oligo(ethylene glycol)-terminated alkanethiol self-assembled monolayers, Langmuir, 2000, 16, 8829-8841.

98 R. L. C. Wang, H. J. Kreuzer and M. Grunze, Molecular conformation and solvation of oligo(ethylene glycol)terminated self-assembled monolayers and their resistance to protein adsorption, J. Phys. Chem. B, 1997, 101, 9767-9773. 
99 I. Szleifer, Protein adsorption on surfaces with grafted polymers: A theoretical approach, Biophys. J., 1997, 72, 595-612.

100 S. Krishnan, C. J. Weinman and C. K. Ober, Advances in polymers for anti-biofouling surfaces, J. Mater. Chem., 2008, 18, 3405-3413.

101 J. D. Andrade, R. N. King, D. E. Gregonis and D. L. Coleman, Surface Characterization of Poly(Hydroxyethyl Methacrylate) and Related Polymers 1. Contact-Angle Methods in Water, J. Polym. Sci., Polym. Symp., 1979, 313-336.

102 M. Heuberger, T. Drobek and N. D. Spencer, Interaction forces and morphology of a protein-resistant poly(ethylene glycol) layer, Biophys. J., 2005, 88, 495-504.

103 N. V. Efremova, S. R. Sheth and D. E. Leckband, Proteininduced changes in poly(ethylene glycol) brushes: Molecular weight and temperature dependence, Langmuir, 2001, 17, 7628-7636.

104 W. Taylor and R. A. L. Jones, Protein adsorption on wellcharacterized polyethylene oxide brushes on gold: Dependence on molecular weight and grafting density, Langmuir, 2013, 29, 6116-6122.

105 G. L. Kenausis, J. Voros, D. L. Elbert, N. P. Huang, R. Hofer, L. Ruiz-Taylor, M. Textor, J. A. Hubbell and N. D. Spencer, Poly(L-lysine)-g-poly(ethylene glycol) layers on metal oxide surfaces: Attachment mechanism and effects of polymer architecture on resistance to protein adsorption, J. Phys. Chem. B, 2000, 104, 3298-3309.

106 R. Michel, S. Pasche, M. Textor and D. G. Castner, Influence of PEG architecture on protein adsorption and conformation, Langmuir, 2005, 21, 12327-12332.

107 S. R. Benhabbour, L. Liu, H. Sheardown and A. Adronov, Protein resistance of surfaces prepared by chemisorption of monothiolated poly(ethylene glycol) to gold and dendronization with aliphatic polyester dendrons: Effect of hydrophilic dendrons, Macromolecules, 2008, 41, 2567-2576.

108 K. L. Prime and G. M. Whitesides, Adsorption of proteins onto surfaces containing end-attached oligo(ethylene oxide) - a model system using self-assembled monolayers, J. Am. Chem. Soc., 1993, 115, 10714-10721.

109 S. Schilp, A. Kueller, A. Rosenhahn, M. Grunze, M. E. Pettitt, M. E. Callow and J. A. Callow, Settlement and adhesion of algal cells to hexa (ethylene glycol)-containing self-assembled monolayers with systematically changed wetting properties, Biointerphases, 2007, 2, 143-150.

110 S. Schilp, A. Rosenhahn, M. E. Pettitt, J. Bowen, M. E. Callow, J. A. Callow and M. Grunze, Physicochemical properties of (ethylene glycol)-containing self-assembled monolayers relevant for protein and algal cell resistance, Langmuir, 2009, 25, 10077-10082.

111 R. G. Chapman, E. Ostuni, S. Takayama, R. E. Holmlin, L. Yan and G. M. Whitesides, Surveying for surfaces that resist the adsorption of proteins, J. Am. Chem. Soc., 2000, 122, 8303-8304.

112 L. Wu, J. Jasinski and S. Krishnan, Carboxybetaine, sulfobetaine, and cationic block copolymer coatings: A comparison of the surface properties and antibiofouling behavior, J. Appl. Polym. Sci., 2012, 124, 2154-2170.
113 Z. Zhang, S. F. Chen and S. Y. Jiang, Dual-functional biomimetic materials: Nonfouling poly(carboxybetaine) with active functional groups for protein immobilization, Biomacromolecules, 2006, 7, 3311-3315.

114 R. E. Holmlin, X. X. Chen, R. G. Chapman, S. Takayama and G. M. Whitesides, Zwitterionic SAMs that resist nonspecific adsorption of protein from aqueous buffer, Langmuir, 2001, 17, 2841-2850.

115 V. A. Tegoulia, W. S. Rao, A. T. Kalambur, J. R. Rabolt and S. L. Cooper, Surface properties, fibrinogen adsorption, and cellular interactions of a novel phosphorylcholinecontaining self-assembled monolayer on gold, Langmuir, 2001, 17, 4396-4404.

116 K. Matsuura, K. Ohno, S. Kagaya and H. Kitano, Carboxybetaine polymer-protected gold nanoparticles: High dispersion stability and resistance against non-specific adsorption of proteins, Macromol. Chem. Phys., 2007, 208, 862-873.

117 W. W. Zhao, Q. Ye, H. Y. Hu, X. L. Wang and F. Zhou, Grafting zwitterionic polymer brushes via electrochemical surface-initiated atomic-transfer radical polymerization for anti-fouling applications, J. Mater. Chem. B, 2014, 2, 5352-5357.

118 R. Yang, H. Jang, R. Stocker and K. K. Gleason, Synergistic prevention of biofouling in seawater desalination by zwitterionic surfaces and low-Level Chlorination, Adv. Mater., 2014, 26, 1711-1718.

119 R. Quintana, D. Janczewski, V. A. Vasantha, S. Jana, S. S. C. Lee, F. J. Parra-Velandia, S. F. Guo, A. Parthiban, S. L. M. Teo and G. J. Vancso, Sulfobetaine-based polymer brushes in marine environment: Is there an effect of the polymerizable group on the antifouling performance?, Colloids Surf., B, 2014, 120, 118-124.

120 Z. Zhang, J. A. Finlay, L. F. Wang, Y. Gao, J. A. Callow, M. E. Callow and S. Y. Jiang, Polysulfobetaine-grafted surfaces as environmentally benign ultralow fouling marine coatings, Langmuir, 2009, 25, 13516-13521.

121 X. Y. Cao, M. E. Pettit, S. L. Conlan, W. Wagner, A. D. Ho, A. S. Clare, J. A. Callow, M. E. Callow, M. Grunze and A. Rosenhahn, Resistance of polysaccharide coatings to proteins, hematopoietic cells, and marine organisms, Biomacromolecules, 2009, 10, 907-915.

122 A. J. De Kerchove and M. Elimelech, Calcium and magnesium cations enhance the adhesion of motile and nonmotile Pseadomonas aeruginosa on alginate films, Langmuir, 2008, 24, 3392-3399.

123 R. S. Kane, P. Deschatelets and G. M. Whitesides, Kosmotropes form the basis of protein-resistant surfaces, Langmuir, 2003, 19, 2388-2391.

124 S. J. Dilly, M. P. Beecham, S. P. Brown, J. M. Griffin, A. J. Clark, C. D. Griffin, J. Marshall, R. M. Napier, P. C. Taylor and A. Marsh, Novel tertiary amine oxide surfaces that resist nonspecific protein adsorption, Langmuir, 2006, 22, 8144-8150.

125 I. Banerjee, R. C. Pangule and R. S. Kane, Antifouling coatings: Recent developments in the design of surfaces 
that prevent fouling by proteins, bacteria, and marine organisms, Adv. Mater., 2011, 23, 690-718.

126 T. Ederth, M. E. Pettitt, P. Nygren, C. X. Du, T. Ekblad, Y. Zhou, M. Falk, M. E. Callow, J. A. Callow and B. Liedberg, Interactions of zoospores of Ulva linza with Arginine-rich oligopeptide monolayers, Langmuir, 2009, 25, 9375-9383.

127 M. Wyszogrodzka and R. Haag, Synthesis and characterization of glycerol dendrons, self-assembled monolayers on gold: A detailed study of their protein resistance, Biomacromolecules, 2009, 10, 1043-1054.

128 Z. L. Zhou, D. R. Calabrese, W. Taylor, J. A. Finlay, M. E. Callow, J. A. Callow, D. Fischer, E. J. Kramer and C. K. Ober, Amphiphilic triblock copolymers with PEGylated hydrocarbon structures as environmentally friendly marine antifouling and fouling-release coatings, Biofouling, 2014, 30, 589-604.

129 C. FreijLarsson, T. Nylander, P. Jannasch and B. Wesslen, Adsorption behaviour of amphiphilic polymers at hydrophobic surfaces: Effects on protein adsorption, Biomaterials, 1996, 17, 2199-2207.

130 S. Krishnan, R. Ayothi, A. Hexemer, J. A. Finlay, K. E. Sohn, R. Perry, C. K. Ober, E. J. Kramer, M. E. Callow, J. A. Callow and D. A. Fischer, Anti-biofouling properties of comblike block copolymers with amphiphilic side chains, Langmuir, 2006, 22, 5075-5086.

131 J. T. Koberstein, Molecular design of functional polymer surfaces, J. Polym. Sci., Part B: Polym. Phys., 2004, 42, 2942-2956.

132 J. K. Pike and T. Ho, Water-induced surface rearrangements of Poly(dimethylsiloxane-urea-urethane) segmented block-copolymers, Chem. Mater., 1996, 8, 856-860.

133 A. C. C. Esteves, I. D. Günbas, J. M. van Riel, B. A. J. Noordover, G. de With and R. A. T. M. van Benthem, Time-resolved surface rearrangements of polymer films monitored by dynamic recovery contact angle (DRCA), RSC Adv., 2014, 4, 20094-20101.

134 J. Verran and R. D. Boyd, The relationship between substratum surface roughness and microbiological and organic soiling: a review., Biofouling, 2001, 17, 59-71.

135 R. L. Fletcher and M. E. Callow, The Settlement, Attachment and Establishment of Marine Algal Spores, Eur. J. Phycol., 1992, 27, 303-329.

136 M. E. Callow, A. R. Jennings, A. B. Brennan, C. E. Seegert, A. Gibson, L. Wilson, A. Feinberg, R. Baney and J. A. Callow, Microtopographic cues for settlement of zoospores of the green fouling alga Enteromorpha, Biofouling, 2002, 18, 237-245.
137 M. L. Carman, T. G. Estes, A. W. Feinberg, J. F. Schumacher, W. Wilkerson, L. H. Wilson, M. E. Callow, J. A. Callow and A. B. Brennan, Engineered antifouling microtopographies correlating wettability with cell attachment, Biofouling, 2006, 22, 11-21.

138 J. S. Chung, B. G. Kim, S. Shim, S. E. Kim, E. H. Sohn, J. Yoon and J. C. Lee, Silver-perfluorodecanethiolate complexes having superhydrophobic, antifouling, antibacterial properties, J. Colloid Interface Sci., 2012, 366, 64-69.

139 J. Chapman and F. Regan, Nanofunctionalized superhydrophobic antifouling coatings for environmental sensor applications - Advancing deployment with answers from nature, Adv. Eng. Mater., 2012, 14, B175-B184.

140 A. J. Scardino, H. Zhang, D. J. Cookson, R. N. Lamb and R. de Nys, The role of nano-roughness in antifouling, Biofouling, 2009, 25, 757-767.

$141 \mathrm{~J}$. M. Hills and J. C. Thomason, The effect of scales of surface roughness on the settlement of barnacle (Semibalanus balanoides) cyprids, Biofouling, 1998, 12, 57-69.

142 L. Lapointe and E. Bourget, Influence of substratum heterogeneity scales and complexity on a temperate epibenthic marine community, Mar. Ecol.: Prog. Ser., 1999, 189, 159-170.

143 S. Petronis, K. Berntsson, J. Gold and P. Gatenholm, Design and microstructuring of PDMS surfaces for improved marine biofouling resistance, J. Biomater. Sci., Polym. Ed., 2000, 11, 1051-1072.

144 C. S. Gudipati, C. M. Greenlief, J. A. Johnson, P. Prayongpan and K. L. Wooley, Hyperbranched fluoropolymer and linear poly(ethylene glycol) based amphiphilic crosslinked networks as efficient antifouling coatings: An insight into the surface compositions, topographies, and morphologies, J. Polym. Sci., Part A: Polym. Chem., 2004, 42, 6193-6208.

145 C. S. Gudipati, J. A. Finlay, J. A. Callow, M. E. Callow and K. L. Wooley, The antifouling and fouling-release perfomance of hyperbranched fluoropolymer (HBFP)-poly(ethylene glycol) (PEG) composite coatings evaluated by adsorption of biomacromolecules and the green fouling alga Ulva, Langmuir, 2005, 21, 3044-3053.

146 N. Y. Kostina, S. Sharifi, A. D. Pereira, J. Michalek, D. W. Grijpma and C. Rodriguez-Emmenegger, Novel antifouling selfhealing poly(carboxybetaine methacrylamide-co-HEMA) nanocomposite hydrogels with superior mechanical properties, J. Mater. Chem. B, 2013, 1, 5644-5650.

147 H. Kuroki, I. Tokarev, D. Nykypanchuk, E. Zhulina and S. Minko, Stimuli-responsive materials with self-healing antifouling surface via 3D polymer grafting, Adv. Funct. Mater., 2013, 23, 4593-4600. 